\title{
Characterization of The Dalles Dam Spillbay 6 Vortex Using Surface Entrained Sensor Fish Device: Preliminary Report
}

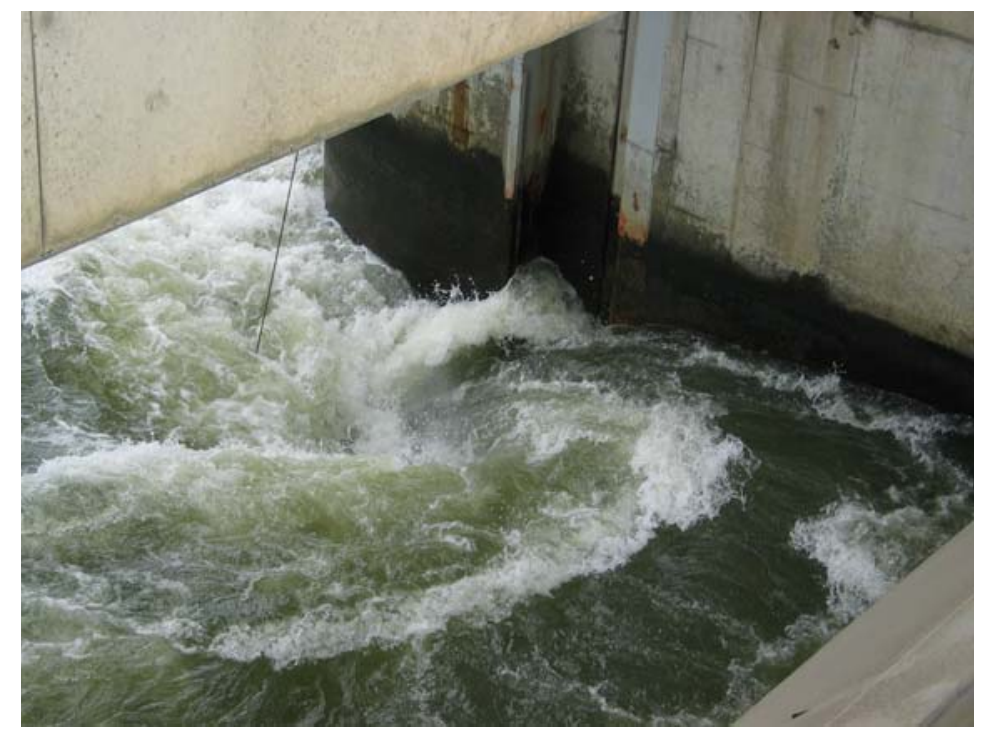

\section{Z. Deng}

M. C. Richmond

T. J. Carlson

Final Report

June 2006

Prepared for the U.S. Army Corps of Engineers

Portland District, Portland, Oregon

Under a Related Services Agreement

with the U.S. Department of Energy

Contract DE-AC05-76RL01830

\section{Pacific Northwest \\ National Laboratory}

Operated by Battelle for the

U.S. Department of Energy 


\title{
DISCLAIMER
}

This report was prepared as an account of work sponsored by an agency of the United States Government. Neither the United States Government nor any agency thereof, nor Battelle Memorial Institute, nor any of their employees, makes any warranty, express or implied, or assumes any legal liability or responsibility for the accuracy, completeness, or usefulness of any information, apparatus, product, or process disclosed, or represents that its use would not infringe privately owned rights. Reference herein to any specific commercial product, process, or service by trade name, trademark, manufacturer, or otherwise does not necessarily constitute or imply its endorsement, recommendation, or favoring by the United States Government or any agency thereof, or Battelle Memorial Institute. The views and opinions of authors expressed herein do not necessarily state or reflect those of the United States Government or any agency thereof.

\author{
PACIFIC NORTHWEST NATIONAL LABORATORY \\ operated by \\ BATTELLE \\ for the \\ UNITED STATES DEPARTMENT OF ENERGY \\ under Contract DE-AC05-76RL01830
}

Printed in the United States of America
Available to DOE and DOE contractors from the Office of Scientific and Technical Information,
P.O. Box 62, Oak Ridge, TN 37831-0062;
ph: (865) 576-8401
fax: $(865) 576-5728$
email: reports@adonis.osti.gov

\footnotetext{
Available to the public from the National Technical Information Service, U.S. Department of Commerce, 5285 Port Royal Rd., Springfield, VA 22161 ph: (800) 553-6847 fax: $(703) 605-6900$ email: orders@ntis.fedworld.gov online ordering: http://www.ntis.gov/ordering.htm
}

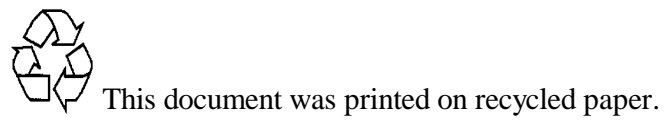




\section{Characterization of The Dalles Dam Spillbay 6 Vortex Using Surface Entrained Sensor Fish Device: Preliminary Report}

Z. Deng

M. C. Richmond

T. J. Carlson

Final Report

June 2006

Prepared for the U.S. Army Corps of Engineers

Portland District, Portland, Oregon

Under a Related Services Agreement

with the U.S. Department of Energy

Contract DE-AC05-76RL01830

Pacific Northwest National Laboratory

Richland, Washington 99352 



\section{Summary}

This document summarizes the pilot study to characterize The Dalles Dam spillbay 6 vortex using a surface-entrained Sensor Fish device. It was conducted by Pacific Northwest National Laboratory (PNNL) on April 13 and 14, 2006. The total spill was controlled at approximately $110 \mathrm{kcfs}$, the forebay elevation was about $158 \mathrm{ft}$, and the discharge of Bay 6 at the tested gate opening of 13 or $14 \mathrm{ft}$ was approximately from 18 to $20 \mathrm{kcfs}$.

The objectives of the full study are to 1) develop baseline conditions for the detailed analysis of Sensor Fish measurements by deploying Sensor Fish in different surface locations in the vortex periphery; 2) observe the entrainment pattern and extract hydraulic data of interest such as acceleration, rotation, pressure, and estimated velocity of the Sensor Fish or drogues; and 3) integrate the experimental results with companion computational fluid dynamics (CFD) simulations and inertial particle tracking studies.

Because higher-than-expected river discharge led to the failure of the submerged release pipe at Bay 6, it was not possible to perform the full study as planned. The limited pilot study was undertaken to collect Sensor Fish data from surface release and to test the surface release mechanism. The full study may be completed at a later date when river discharge and water temperature are within the range required by the study design.

A total of 12 Sensor Fish were released in the surface at the upstream edge, left edge, downstream edge, and the core of the vortex at Bay 6. Because of the high discharge, the vortex patterns at the test condition were less organized than the patterns observed at lower discharges. Compared with the Sensor Fish released at mid-bay at Bay 6, Sensor Fish released from the surface at the vortex experienced higher pressure fluctuations, a larger percentage of severe events, and much more rapid angular velocities.

To address the possible causes and biological implications, we need more samples of vortexentrained Sensor Fish and details of non-entrained Sensor Fish released at the same locations upstream of the vortex. These samples would be collected as part of the planned full study. 



\section{Acknowledgments}

Financial support was provided by the U.S. Army Corps of Engineers, Portland District, Portland, Oregon. In particular, the authors would like to thank Laurie Ebner and Randall Lee for their technical guidance and comments and Guy Fielding for his technical assistance. We also like to thank Bob Mueller, Bob Johnson, Mickie Chamness, Mark Weiland, Joanne Duncan, Cindy Rakowski, and John Serkowski at PNNL for their technical assistance and suggestions. Terri Gilbride was the technical editor for this document. 



\section{Contents}

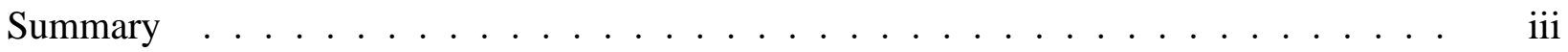

Acknowledgments .......................... . . . .

1.0 Introduction . . . . . . . . . . . . . . . . . . . . . . . . . 1.1

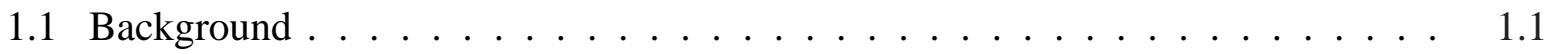

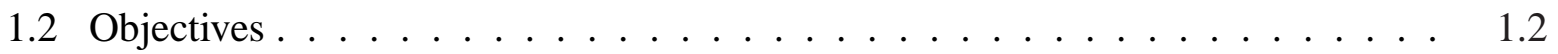

1.3 Overview of this report $\ldots \ldots \ldots \ldots \ldots \ldots \ldots$

2.0 Experimental Methods . . . . . . . . . . . . . . . . . . . . 2.1

2.1 Project Site . . . . . . . . . . . . . . . . . . 2.1

2.2 Sensor Fish Device . . . . . . . . . . . . . . . . . . . . 2.1

2.3 Release Mechanism and Locations . . . . . . . . . . . . . . . . . . . . 2.1

3.0 Preliminary Results and Discussion . . . . . . . . . . . . . . . . . 3.1

3.1 Vortex Generation . . . . . . . . . . . . . . . . . 3.1

3.2 Sensor Fish Measurements . . . . . . . . . . . . . . . . . . . 3.1

4.0 Conclusions and Recommendations _ . . . . . . . . . . . . . . . . . . 4.1

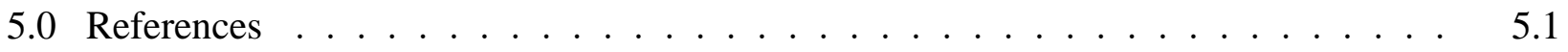

Appendix A - Sensor Fish Data Showing Pressure, Acceleration Magnitude, and Angular Velocity Magnitude Time Histories for Each Release . . . . . . . . . . . . . . . A.1 


\section{Figures}

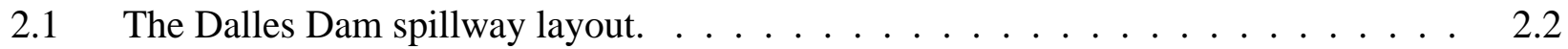

2.2 The Sensor Fish Device is $24.5 \mathrm{~mm}$ in diameter and $90 \mathrm{~mm}$ in length, weighs 42 grams, roughly the same as a yearling salmon smolt and is nearly neutrally buoyant in fresh water. It includes three rate gyros, three linear accelerometers, absolute pressure and temperature transducer. . . . . . . . . . . . . . . .

2.3 Sensor Fish release mechanism: The Sensor Fish was tied with a loop to the snap which was opened by a slight tension $\ldots \ldots \ldots \ldots \ldots . \ldots \ldots$

2.4 Three Sensor Fish were released in the surface at four regions of the vortex: front edge (F1-F3), left edge (L1-L3), back edge (B1-B3), and the core (C1-C3), respectively (look-

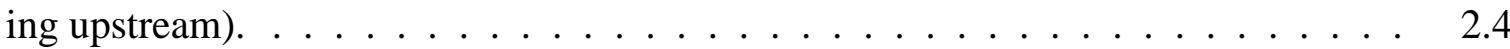

3.1 Vortex scales at different gate openings from 1 to $7 \mathrm{ft}$ : (a) $1.2 \mathrm{ft}$; (b) $2.3 \mathrm{ft}$; (c) $3.3 \mathrm{ft}$;

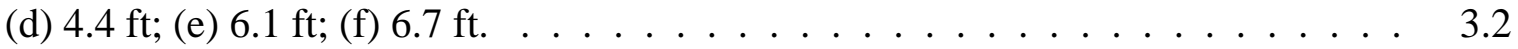

3.2 Vortex scales at different gate openings from 7 to $13 \mathrm{ft}$ : (a) $7.8 \mathrm{ft}$; (b) $8.9 \mathrm{ft}$; (c) 10 ft; (d) $11 \mathrm{ft}$; (e) $12.3 \mathrm{ft}$; (f) $13 \mathrm{ft} . \ldots \ldots \ldots \ldots$

3.3 The scale of the vortex varies as water swirls downward. . . . . . . . . . . . . . 3.4

3.4 An example of measurements by Sensor Fish released from mid-bay at spillbay 6: (a) acceleration; (b) angular velocity. . . . . . . . . . . . . . . . 3.6

3.5 An example of measurements by Sensor Fish released from the front edge of the vortex (Location F2) : (a) acceleration; (b) angular velocity. . . . . . . . . . . . 3.6

3.6 An example of measurements by Sensor Fish released from the left edge of the vortex (Location L2) : (a) acceleration; (b) angular velocity. . . . . . . . . . . . . . .

3.7 An example of measurements by Sensor Fish released from the back edge of the vortex (Location B2) : (a) acceleration; (b) angular velocity. . . . . . . . . . . . . .

3.8 An example of measurements by Sensor Fish released from the core of the vortex (Location C3) : (a) acceleration; (b) angular velocity. . . . . . . . . . . . . 3.8

3.9 An example of Sensor Fish passage without severe events measurements (Location B3) : (a) acceleration; (b) angular velocity. . . . . . . . . . . . . . . 3.8

3.10 An example of measurements by Sensor Fish passing through Unit 9 turbine at Wanapum Dam, 17kcfs : (a) acceleration; (b) angular velocity. . . . . . . . . . . .

3.11 Flow in the spillbay 6 at a discharge of $20 \mathrm{kcfs}$, The Dalles Dam $\ldots \ldots \ldots \ldots$ 
A.1 An example of measurements by Sensor Fish released from the front edge of the vortex (Location F1) : (a) acceleration; (b) angular velocity. . . . . . . . . . . . . . .

A.2 An example of measurements by Sensor Fish released from the front edge of the vortex (Location F2) : (a) acceleration; (b) angular velocity. . . . . . . . . . . . . .

A.3 An example of measurements by Sensor Fish released from the front edge of the vortex (Location F3) : (a) acceleration; (b) angular velocity. . . . . . . . . . . . . .

A.4 An example of measurements by Sensor Fish released from the left edge of the vortex (Location L1) : (a) acceleration; (b) angular velocity. . . . . . . . . . . . . . .

A.5 An example of measurements by Sensor Fish released from the left edge of the vortex (Location L2) : (a) acceleration; (b) angular velocity. . . . . . . . . . . . . .

A.6 An example of measurements by Sensor Fish released from the left edge of the vortex (Location L3) : (a) acceleration; (b) angular velocity. . . . . . . . . . . . . .

A.7 An example of measurements by Sensor Fish released from the back edge of the vortex (Location B1) : (a) acceleration; (b) angular velocity. . . . . . . . . . . . . .

A.8 An example of measurements by Sensor Fish released from the back edge of the vortex (Location B2) : (a) acceleration; (b) angular velocity. . . . . . . . . . . . .

A.9 An example of measurements by Sensor Fish released from the back edge of the vortex (Location B3) : (a) acceleration; (b) angular velocity. . . . . . . . . . . . . .

A.10 An example of measurements by Sensor Fish released from the core of the vortex (Location C1) : (a) acceleration; (b) angular velocity. . . . . . . . . . . . A.6

A.11 An example of measurements by Sensor Fish released from the core of the vortex (Location C2) : (a) acceleration; (b) angular velocity. . . . . . . . . . . . . A.6

A.12 An example of measurements by Sensor Fish released from the core of the vortex (Location C3) : (a) acceleration; (b) angular velocity. . . . . . . . . . . . . . A.7 


\section{Tables}

3.1 Summary of Sensor Fish releases from release point to baffle blocks $\ldots \ldots .5$ 


\subsection{Introduction}

This report describes a pilot study conducted by Pacific Northwest National Laboratory (PNNL) for the U.S. Army Corps of Engineers, Portland District to characterize the vortex at spillbay 6 at The Dalles Dam using surface-entrained Sensor Fish Device in April 2006.

\subsection{Background}

Because of their generally higher survival rate, spillways have been identified by fish management agencies as a preferred alternative for downstream passage of migrating juvenile fish. However, at The Dalles Dam, survival of juvenile salmonids that pass through the spillway is lower than survival through spillways at other mainstem Columbia and Snake River dams. After several years of survival research, it was determined that reduced spill levels result in higher survival rates for fish that passed through the spillway at The Dalles Dam. As a result, spill for juvenile fish passage was set at $40 \%$ of total river flow, a significant reduction from the $64 \%$ spill level previously set for juvenile fish passage. While survival has increased somewhat at the lower spill level, it is still lower than what is observed at most other U.S. Corps of Engineers operated dams in the basin (Normandeau et al. 2003, 2004).

In 2003, the Corps built a spillwall in The Dalles Dam stilling basin as a means to reduce lateral flow in the spilling basin and to further increase survival for juvenile fish that pass through the spillway. Along with the new training wall, new spill patterns were developed that involve spilling mostly through Bays 1-6. The first of a two-year post-construction evaluation was conducted in 2004. Results from a direct survival and injury test showed relatively high direct survival and low injury for fish passing through Bays 2 and 4, but lower-than-expected survival for fish passing through Bay 6 (Normandeau et al. 2005). There are some unique features associated with Bay 6 including a large vortex that forms upstream on the south side of Bay 6 . Passage studies in 2004 indicated that approximately $25 \%$ of the fish passing through the spillway passed through Bay 6 and that survival through that Bay was lower than for fish passing through Bays 1-4. Furthermore, a 3-dimensional acoustic tag study at The Dalles Dam indicated that a large majority of fish passing through Bay 6 passed on the south side of that Bay. During the winter of 2004-05, a hydraulic modeling effort at the Engineer Research and Development Center (ERDC) showed that suspending a stop log in spillbay 6 prevented formation of the large vortex. During February 2005, a brief test at The Dalles Dam was conducted, which verified the physical model results.

Previous investigations of the effect of vortex entrainment on fish and sampling of exposure conditions using Sensor Fish have been very limited. The Sensor Fish is an autonomous sensor device developed by PNNL to better understand the physical conditions fish experience during passage through hydroturbines and other dam bypass alternatives. In another study conducted by Normandeau Associates and PNNL concurrently with this study, live test fish and sensors will be introduced in Bay 4 and Bay 6, using an injection system similar to that used for previous balloon tag studies (Normandeau et al. 2005), into flow upstream of the vortex at depths representative of those used by run-of-river fish. This method of introduction has the potential to place test fish in spill approach flow that better simulates the approach of run-of-river fish to the vortex because fish are released at several elevations upstream of the vortex. By releasing juvenile fish 
and Sensor Fish simultaneously, we can characterize the exposure conditions of juvenile fish using the Sensor Fish measurements. However, due to the complex nature of the water flow structure in the vicinity of the vortex, it is difficult to assess the details of the entrainment of fish and sensor fish. This ambiguity poses a challenge to the interpretation of the fish survival data and detailed analysis of Sensor Fish measurements; these interpretations and analysis are critical for the integration of these results with Computational Fluid Dynamics (CFD) models.

\subsection{Objectives}

The objectives of the full study are to 1) develop baseline conditions for the detailed analysis of Sensor Fish measurements by deploying Sensor Fish in different surface locations in the vortex periphery; 2) observe the entrainment pattern and extract hydraulic data of interest such as acceleration, rotation, pressure, and estimated velocity of Sensor Fish or drogues; and 3) integrate the experimental results with companion CFD simulations and inertial particle tracking studies.

Because higher-than-expected river discharge led to the failure of the submerged release pipe at Bay 6, it was not possible to perform the full study as planned. The limited pilot study was undertaken to collect Sensor Fish data from surface releases and to test the surface release mechanism. The full study may be completed at a later date when river discharge and water temperature are within the range required by the study design.

A total of 12 Sensor Fish were released at the surface at the upstream edge, left edge, downstream edge, and the core of the vortex at Bay 6. Because of the high discharge, the vortex patterns at the test condition were less consistent than the patterns observed at lower discharges. Compared with Sensor Fish released at mid-bay at Bay 6, the Sensor Fish released from the surface at the vortex experienced higher pressure fluctuations, a larger percentage of severe events, and much more rapid angular velocities.

\subsection{Overview of this report}

Chapter 2 provides an overview of the project site and experimental methods. Chapter 3 describes the pilot study conducted by PNNL in April 2006. Chapter 4 lists conclusions and recommendations for future studies based on findings from this pilot study. Appendix A includes all the Sensor Fish data collected in this pilot study. 


\subsection{Experimental Methods}

\subsection{Project Site}

The Dalles Dam is located at river kilometer 306 on the main stem Columbia River. The powerhouse was completed in 1957 and is located between Oregon and Washington. The Dalles Dam consists of a 22-unit powerhouse, a 23-gate spillway, and a navigation lock. The configuration of this facility is such that the spillway is perpendicular to the river, while the powerhouse is parallel to the river. The spillway has an overall length of 1,370 ft and contains 23 gates, each $50 \mathrm{ft}$ wide. Spill is regulated by tainter gates that pass water at a maximum depth of approximately 40 $\mathrm{ft}$ below the upstream water surface. Water discharged through the tainter gates plunges approximately $50 \mathrm{ft}$ to the stilling basin. A single row of 9 -ft-high by 10 -ft-wide concrete baffles are located in the stilling basin to dissipate energy. An end sill lies downstream of the baffles; this structure is a 13-ft-high vertical wall and lies approximately $10 \mathrm{ft}$ below normal tailrace elevation (Fig. 2.1).

\subsection{Sensor Fish Device}

The Sensor Fish device (Fig. 2.2) is an autonomous device being developed at PNNL for the U.S. Department of Energy and Army Corps of Engineers to better understand the physical conditions fish experience during passage through hydroturbines and other dam bypass alternatives (Carlson and Duncan 2003, Deng et al. 2004). It is $24.5 \mathrm{~mm}$ in diameter and $90 \mathrm{~mm}$ in length and weighs 42 grams. It is roughly the same size as a yearling salmon smolt and, like a fish, is nearly neutrally buoyant in fresh water. It measures the three components of linear acceleration (up-down, forward-back, and side-to-side), the three components of angular velocity (pitch, roll, and yaw), and the absolute pressure and temperature at a sampling frequency of $2,000 \mathrm{~Hz}$ (Deng et al. 2004). All devices were tested in a calibration apparatus. The relative errors of both the linear acceleration and angular velocity measurements were less than $5 \%$.

In actual use, the Sensor Fish is only one part of a system necessary to acquire data on hydraulic conditions. There are other requirements related to deploying and retrieving the Sensor Fish, downloading acquired data, and analyzing and interpreting data. The system consists of modules that charge its internal battery, program the sensor settings, acquire data, convert from analog signal to digital form, download and analyze the data, and interpret the results. The acquired data are stored in an internal memory card and transferred to computers via a wireless infrared link with an external infrared link modem. Analysis of these data permits detailed assessment of the fish passage route, identification of potential problem areas and exposure to significant events such as collisions, strike, shear and severe turbulence. Sensor Fish device data has proven to be an important element in understanding biological test results by linking potential injurious exposures with live test fish injury and mortality observations.

\subsection{Release Mechanism and Locations}

The Sensor Fish were deployed in the surface of the vortex periphery by a lightweight release mechanism (Fig. 2.3). The Sensor Fish were tied with a loop to the snap in the release mechanism, which was controlled by a fishing rod through fishing line. After the Sensor Fish were 

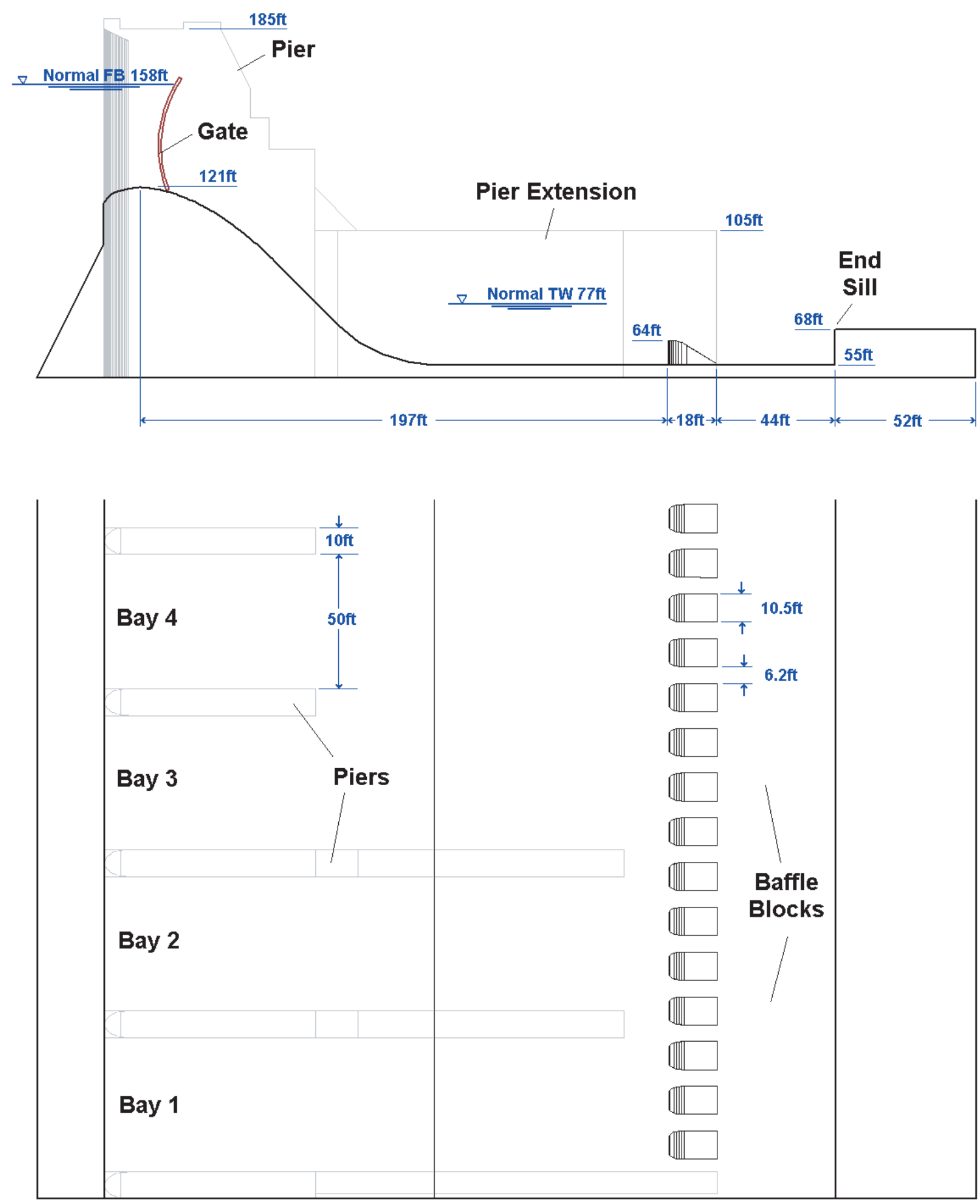

Figure 2.1. The Dalles Dam spillway layout. 


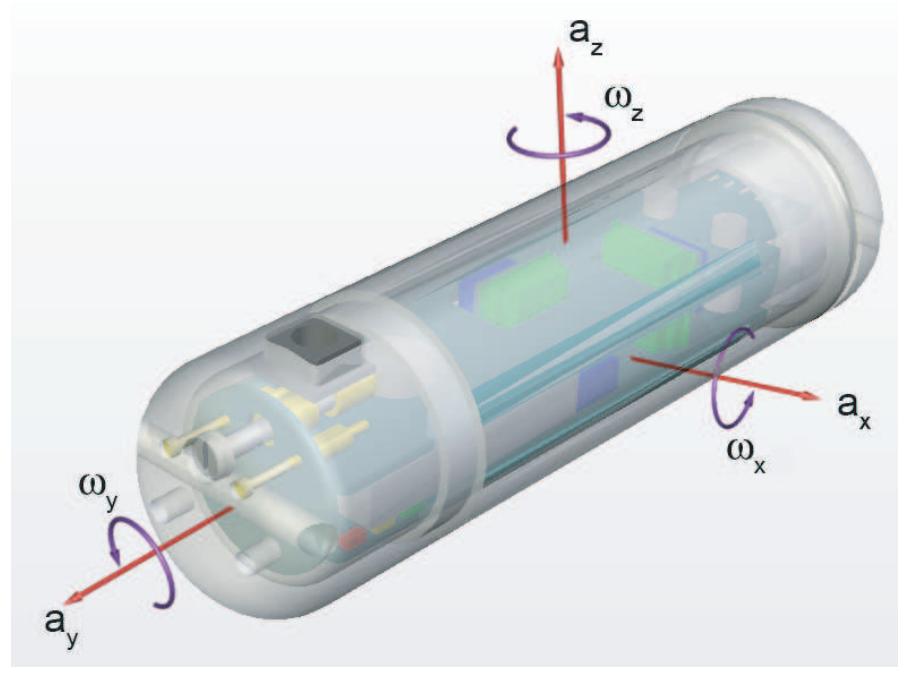

Figure 2.2. The Sensor Fish Device is $24.5 \mathrm{~mm}$ in diameter and $90 \mathrm{~mm}$ in length, weighs 42 grams, roughly the same as a yearling salmon smolt and is nearly neutrally buoyant in fresh water. It includes three rate gyros, three linear accelerometers, absolute pressure and temperature transducer.

lowered about $20 \mathrm{ft}$ from the deck to the predetermined surface location, the fish line was slightly pulled; the resulting tension (jerk) caused the snap in the mechanism to open, the tying loop in the snap fell out and the Sensor Fish was released into the vortex.

A total of 12 valid Sensor Fish data sets at Bay 6 were obtained. They were distributed in the front, front edge (labeled F1 to F3), left edge (L1 to L3), back edge (B1 to B3), and the core (C1 to $\mathrm{C} 3$ ), respectively (Fig. 2.4). All of these releases were entrained in the vortex.

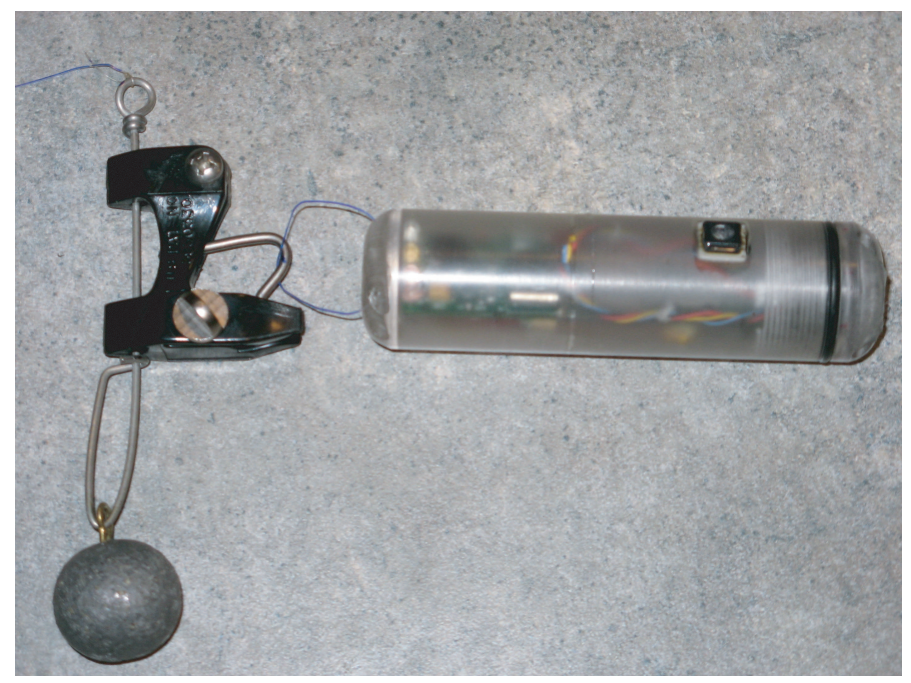

Figure 2.3. Sensor Fish release mechanism: The Sensor Fish was tied with a loop to the snap which was opened by a slight tension 


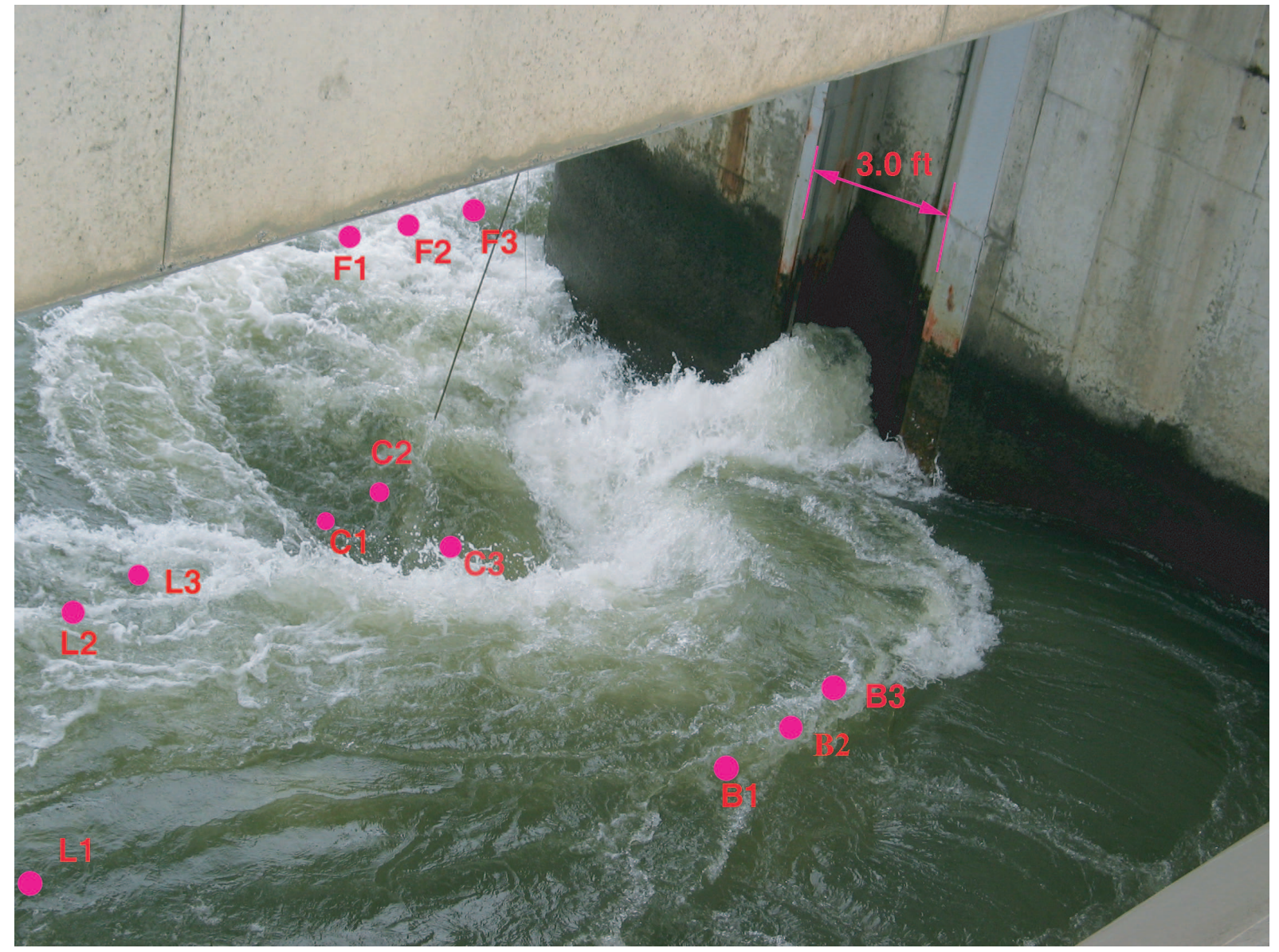

Figure 2.4. Three Sensor Fish were released in the surface at four regions of the vortex: front edge (F1-F3), left edge (L1-L3), back edge (B1-B3), and the core (C1-C3), respectively (looking upstream). 


\subsection{Preliminary Results and Discussion}

All the Sensor Fish releases were conducted on April 13 and 14, 2006. The total spill was controlled at approximately $110 \mathrm{kcfs}$. The spill of Bay 6 was approximately 18 and $20 \mathrm{kcfs}$ for the tested gate openings of 13 and $14 \mathrm{ft}$, respectively. The water surface elevation was about 158 $\mathrm{ft}$ and $82 \mathrm{ft}$ for the forebay and tailrace, respectively.

\subsection{Vortex Generation}

The vortex generation was recorded by a digital camcorder when the tainter gate was lifted from a closed position to $13 \mathrm{ft}$. When the opening was less than $7 \mathrm{ft}$ (Fig. 3.1), the vortex position was relatively stationary, its patterns were organized, and its core was readily identifiable. However, as the gate opening increased, especially at the test condition, the vortex patterns became less consistent (Fig. 3.2).

From observations made during moderate spillway flow discharge, the vortex looked like a Rankine Combined Vortex (RCV) (Rankine 1858, Odgaard 1986). The RCV consists of a vortex core and outer flow zone. In the core, the tangential velocity is proportional to the distance to the center. It is also termed as solid body vortex in this region because the fluid rotates like a solid body. In the outer flow zone, the velocity has only an azimuthal component and is inversely proportional to the distance to the center. It is also called a potential flow zone because there is no vorticity in this region. RCV is usually described mathematically as:

$$
V_{r}(r)= \begin{cases}C r, & \text { if } r \leq r_{0} \\ \frac{C r_{0}^{2}}{r}, & \text { if } r>r_{0}\end{cases}
$$

where $r_{0}$ is the core radius and $C$ is a constant.

In the vortex zone, the pressure on the outside is higher than the pressure inside, so there is a pressure difference that may entrain fish from ambient flows towards the vortex center. The scale and strength of the vortex vary as water swirls downward (Fig. 3.3) and the pressure distribution also varies with elevation. Therefore, the entrainment mechanics can be different for fish approaching the vortex at different elevations.

\subsection{Sensor Fish Measurements}

For a typical Sensor Fish released in the mid-bay, the pressure and acceleration measurements have characteristic signatures for particular passage events that are very helpful in identifying the occurrence and location of severe events, such as collisions and shear events. Readily identifiable are the time of passage from the injection pipe exit into the forebay, passage under the tainter gate, time in the spillway chute, transition to the tailrace, and passage in the tailrace (Fig. 3.4). These distinctive signature events are used to estimate the probable location and time of collision or shear exposure events and timing information for integration with CFD results. In this study we found there was an increase of acceleration and angular velocity when the Sensor Fish passed under the tainter gate. The passage was smooth with very small acceleration and angular velocity in the spillbay chute until it entered the tail water and was close to the baffle blocks. In 

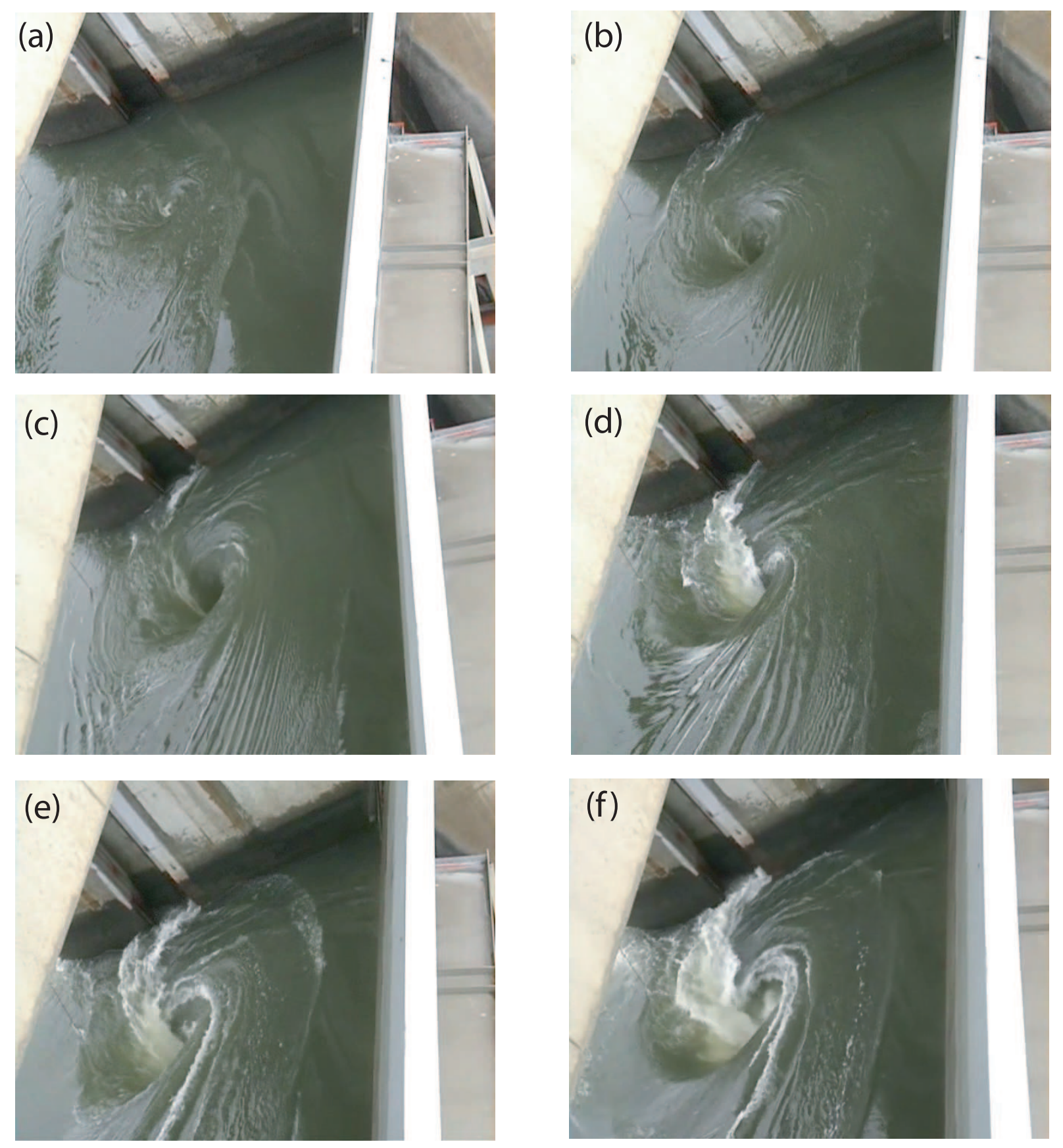

Figure 3.1. Vortex scales at different gate openings from 1 to $7 \mathrm{ft}$ : (a) $1.2 \mathrm{ft}$; (b) $2.3 \mathrm{ft}$; (c) 3.3 $\mathrm{ft}$; (d) $4.4 \mathrm{ft}$; (e) $6.1 \mathrm{ft}$; (f) $6.7 \mathrm{ft}$. 

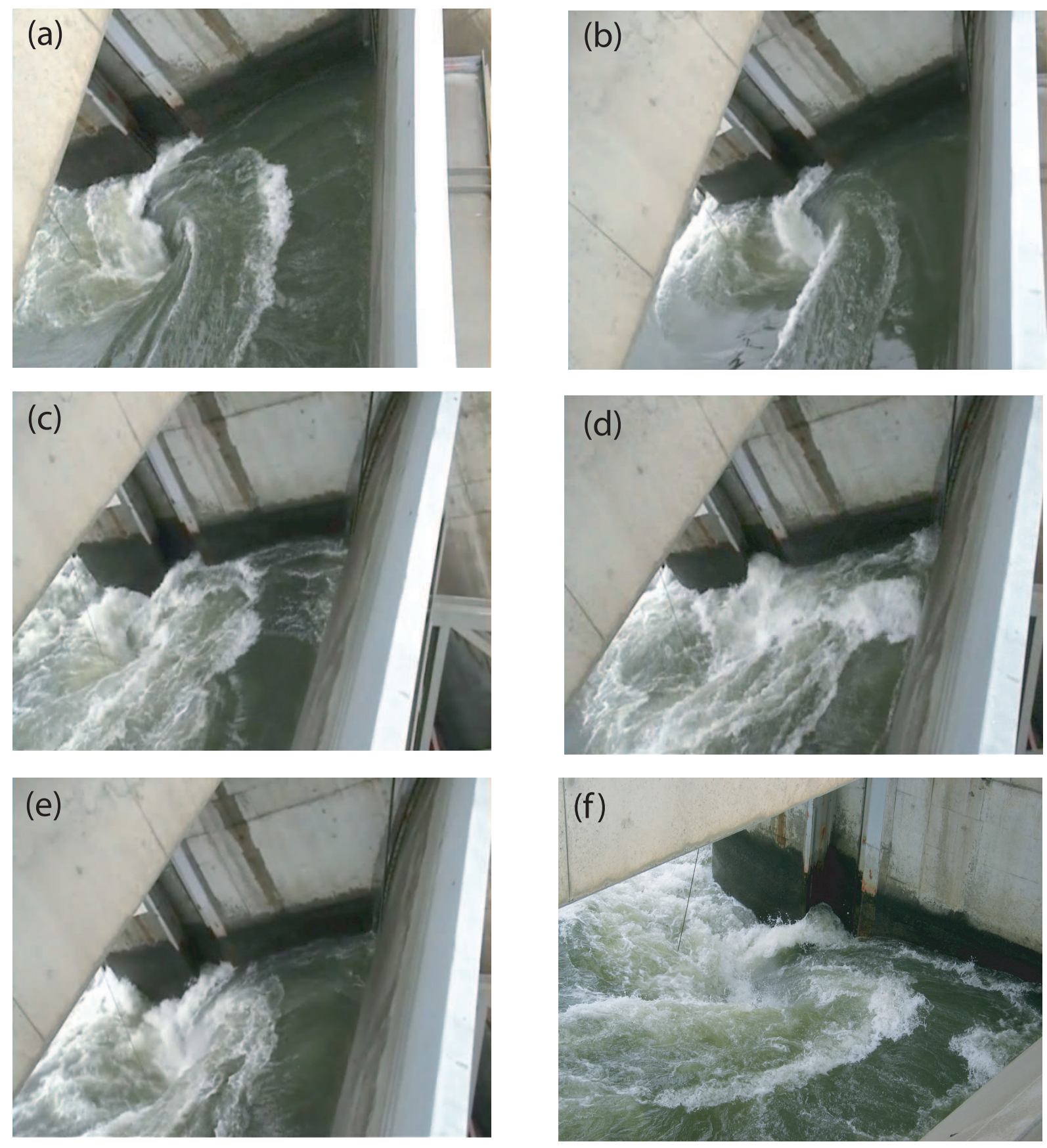

Figure 3.2. Vortex scales at different gate openings from 7 to $13 \mathrm{ft}$ : (a) $7.8 \mathrm{ft}$; (b) $8.9 \mathrm{ft}$; (c) 10 $\mathrm{ft}$; (d) $11 \mathrm{ft}$; (e) $12.3 \mathrm{ft}$; (f) $13 \mathrm{ft}$. 


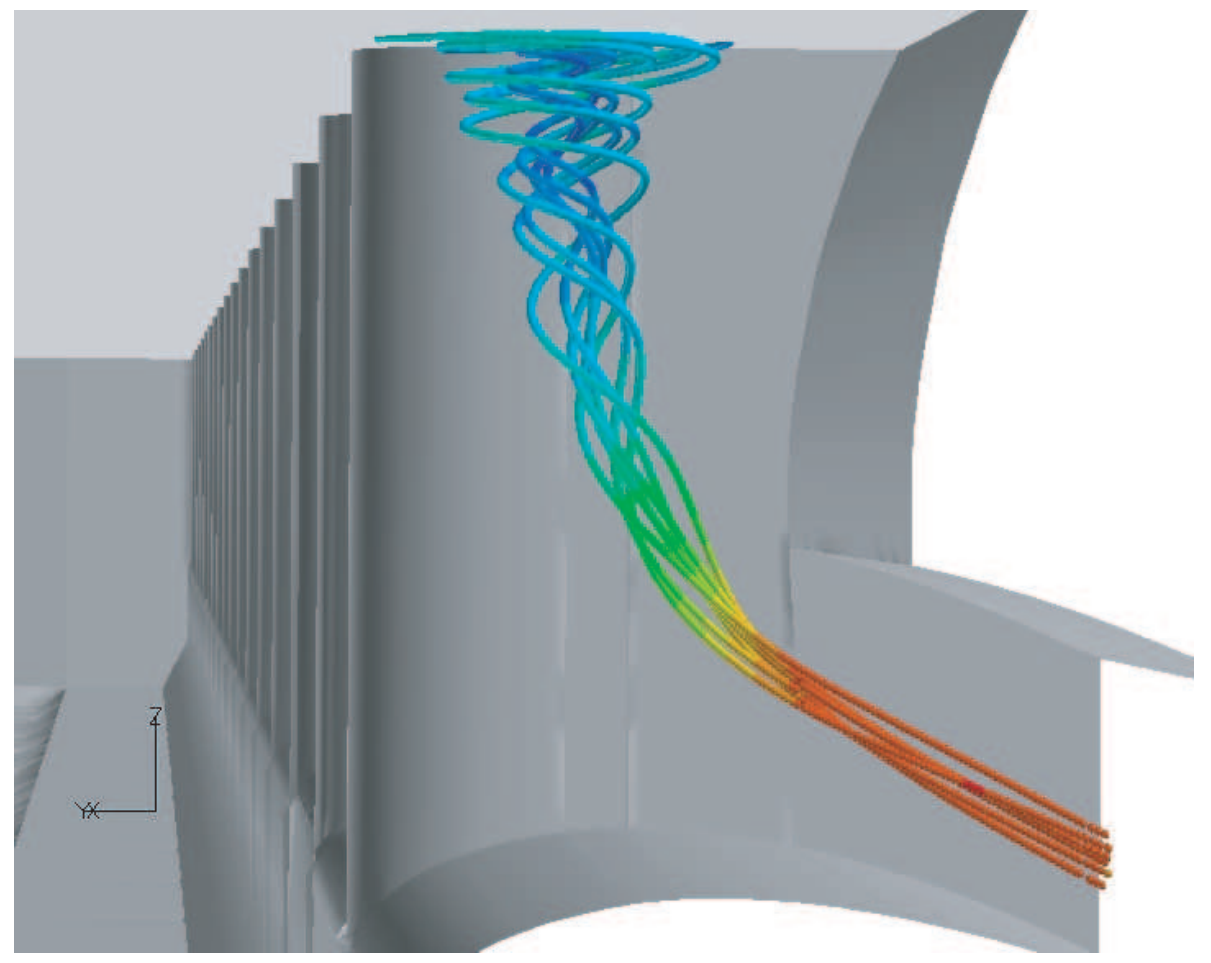

Figure 3.3. The scale of the vortex varies as water swirls downward.

the tailrace immediately after the spillway, both the acceleration and angular velocity increased significantly because of the turbulent nature in this flow region.

A total of 12 Sensor Fish were released in the surface at the upstream edge, left edge, downstream edge, and the core of the vortex (Fig. 2.4). The travel time from the front edge to the tainter gate was approximately 4.3 seconds, while it took only about one second to reach the gate for Sensor Fish released at the vortex core surface (Table 3.1). From the entry point to the baffle blocks, eight out of the 12 releases had at least one severe event. An acceleration threshold of $95 \mathrm{~g}$ was selected as the definition of severe events from our previous laboratory investigations (Deng et al. 2005, Richmond et al. 2006).

Figures 3.5 to 3.8 show examples of time histories for Sensor Fish acceleration and angular velocity for each of the four regions, respectively. Compared to the Sensor Fish released at mid-bay (Fig. 3.4), all Sensor Fish released at the surface of the vortex sustained much higher angular velocities throughout the passage, even at the spillway chute, where Sensor Fish from the mid-bay release usually experienced only small angular velocities. This statement was also true even if the Sensor Fish didn't encounter any severe events from the entry to the baffle block region (Fig. 3.9). If a juvenile fish is entrained in a similar fashion, the higher angular velocity could lead to disorientation or loss of equilibrium, and therefore could lead to an increase of its vulnerability to predators and indirect mortality. In addition, the pressure measurements indicate that the Sensor Fish entrained in the vortex experience higher pressure fluctuations, even though further experiments need to be conducted to study whether the source was due to the nature of vortex passage or the possible large slip velocity between the Sensor Fish pressure transducer and the surrounding water. 
Table 3.1. Summary of Sensor Fish releases from release point to baffle blocks

\begin{tabular}{ccccccccc}
\hline \hline $\begin{array}{c}\text { Release } \\
\text { ID }\end{array}$ & $\begin{array}{c}\text { Release } \\
\text { location }\end{array}$ & $\begin{array}{c}\text { time from } \\
\text { entry to } \\
\text { gate }(\mathrm{s})\end{array}$ & $\begin{array}{c}\text { Severe } \\
\text { events } \\
(|a| \geq 95 g)\end{array}$ & $\begin{array}{c}\text { Gate } \\
\text { opening } \\
(\mathrm{ft})\end{array}$ & $\begin{array}{c}\text { Tail } \\
\text { water } \\
(\mathrm{ft})\end{array}$ & $\begin{array}{c}\text { Fore- } \\
\text { Bay } \\
(\mathrm{ft})\end{array}$ & $\begin{array}{c}\text { Total } \\
\text { spill } \\
(\mathrm{kcfs})\end{array}$ & $\begin{array}{c}\text { Bay 6 } \\
\text { spill } \\
(\mathrm{kcfs})\end{array}$ \\
\hline B1 & Back edge & 2.80 & chute & 13 & 81.69 & 158.20 & 110.4 & 18.4 \\
B2 & Back edge & 2.20 & chute & 13 & 81.69 & 158.20 & 110.4 & 18.4 \\
B3 & Back edge & 1.50 & None & 13 & 81.35 & 157.89 & 105.9 & 17.7 \\
C1 & Core & 1.13 & chute & 13 & 81.69 & 158.20 & 110.4 & 18.4 \\
C2 & Core & 1.00 & None & 14 & 83.15 & 157.98 & 123.0 & 19.8 \\
C3 & Core & 1.16 & chute & 13 & 81.69 & 158.20 & 110.4 & 18.4 \\
F1 & Front edge & 4.20 & Gate or wall & 14 & 82.11 & 157.84 & 116.3 & 19.4 \\
F2 & Front edge & 4.25 & Baffle block & 14 & 82.11 & 157.84 & 116.3 & 19.4 \\
F3 & Front edge & 4.70 & Gate or wall & 13 & 82.00 & 158.20 & 110.4 & 18.4 \\
L1 & Left edge & 3.1 & None & 13 & 81.90 & 157.89 & 110.1 & 18.3 \\
L2 & Left edge & 2.6 & Baffle block & 14 & 82.81 & 158.41 & 123.9 & 19.9 \\
L3 & Left edge & 1.6 & None & 13 & 81.79 & 157.89 & 109.8 & 18.3 \\
\hline \hline
\end{tabular}

The large angular velocity experienced by Sensor Fish within the vortex is comparable to that experienced by Sensor Fish passing through a turbine (Fig. 3.10). Around a turbine, in addition to the downward flow, there is very strong angular momentum because of the rotation of the turbine and its blades. In some sense, the flow in the vortex at spillbay 6 is analogous to the swirling downward flow around a turbine. In addition, similar to turbine-passage fish in the vicinity of the turbine, spillway-passage fish also undergo a sharp pressure change within a fraction of second under the tainter gate at the spillbay. Therefore, if we exclude possibility of mechanical injury due to the strike by the turbine blades, fish entrained into the spillbay vortex during spillway passage may sustain similar complications as those fish passing through a turbine.

Finally, the vortex is close to the south wall of spillbay 6 , and the flow on this side appears to be more turbulent and unsteady than that in the middle (Fig. 3.11). Therefore, it raises a question about the possible cause of the high percentage of severe events and large angular velocity for the vortex-entrained Sensor Fish: is it because of the presence of the wall and the the Sensor Fish's proximity to the side wall or is it the turbulent nature of this flow region? This issue will be addressed in the full study by directly comparing vortex-entrained Sensor Fish releases with non-entrained Sensor Fish, which are released at the same locations in front of the vortex. 

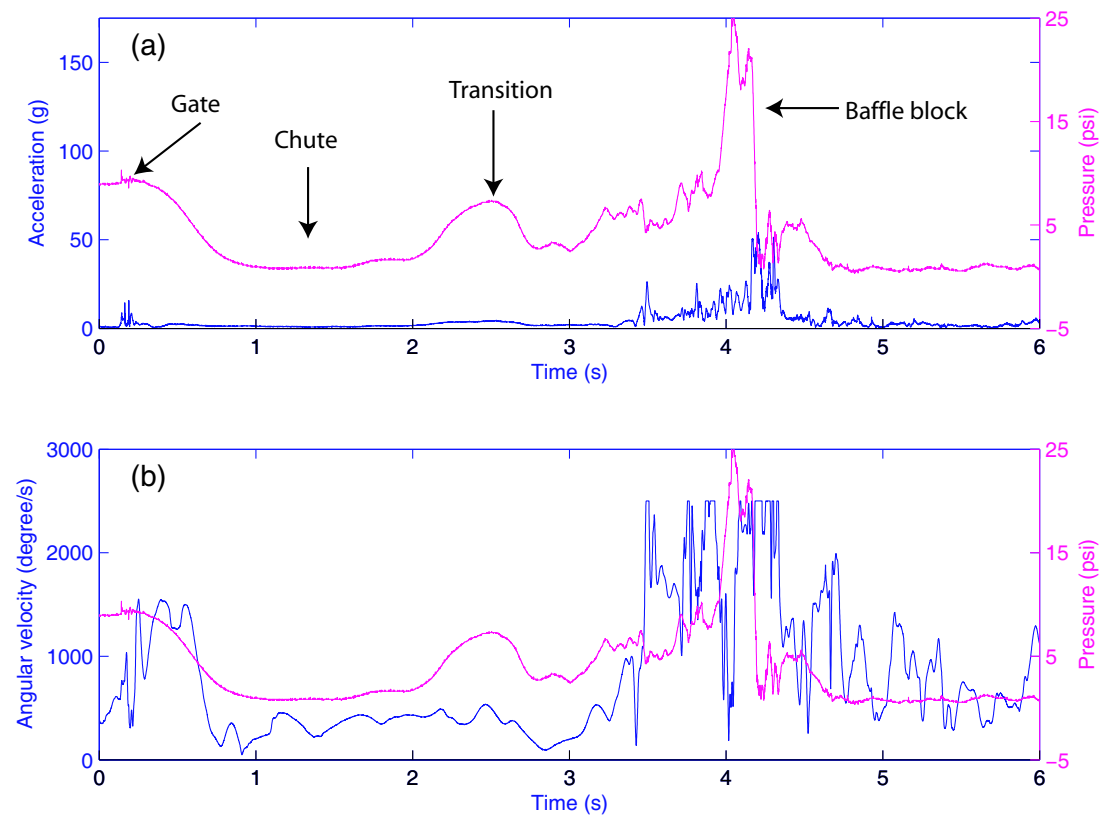

Figure 3.4. An example of measurements by Sensor Fish released from mid-bay at spillbay 6: (a) acceleration; (b) angular velocity.
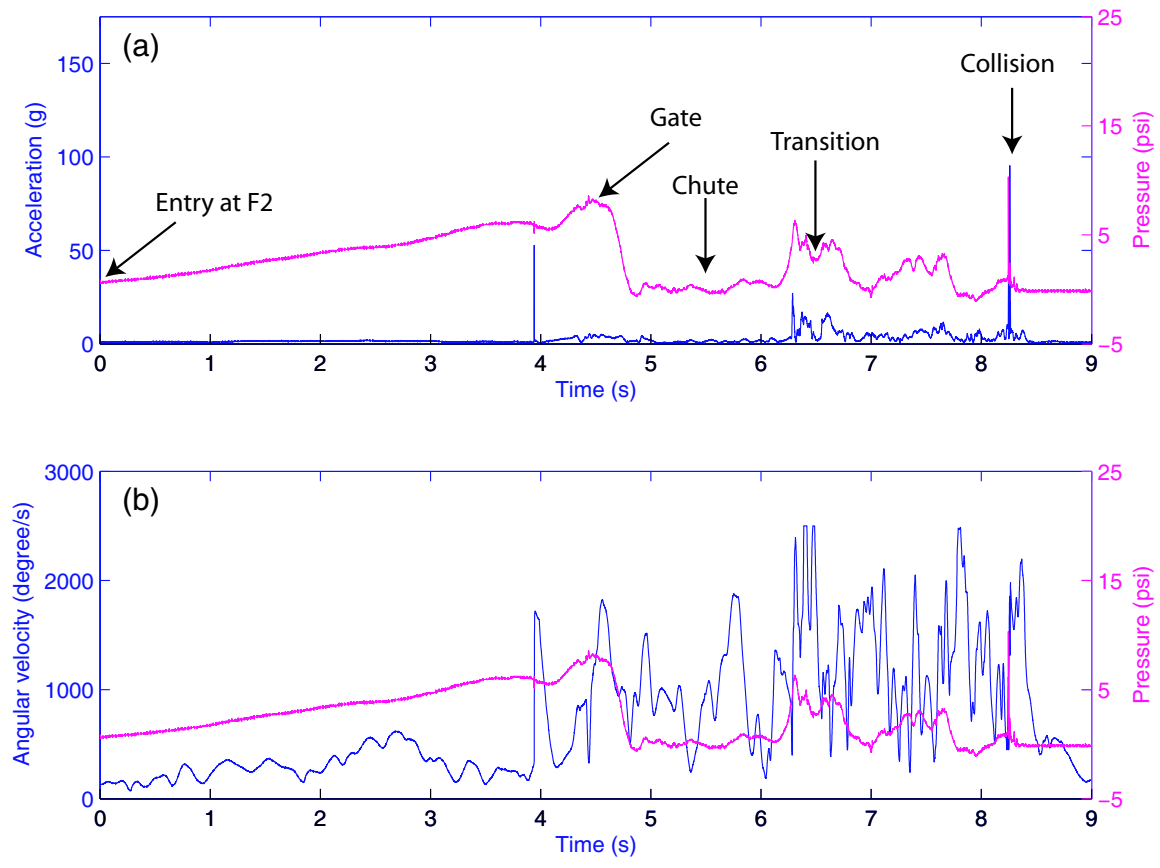

Figure 3.5. An example of measurements by Sensor Fish released from the front edge of the vortex (Location F2) : (a) acceleration; (b) angular velocity. 

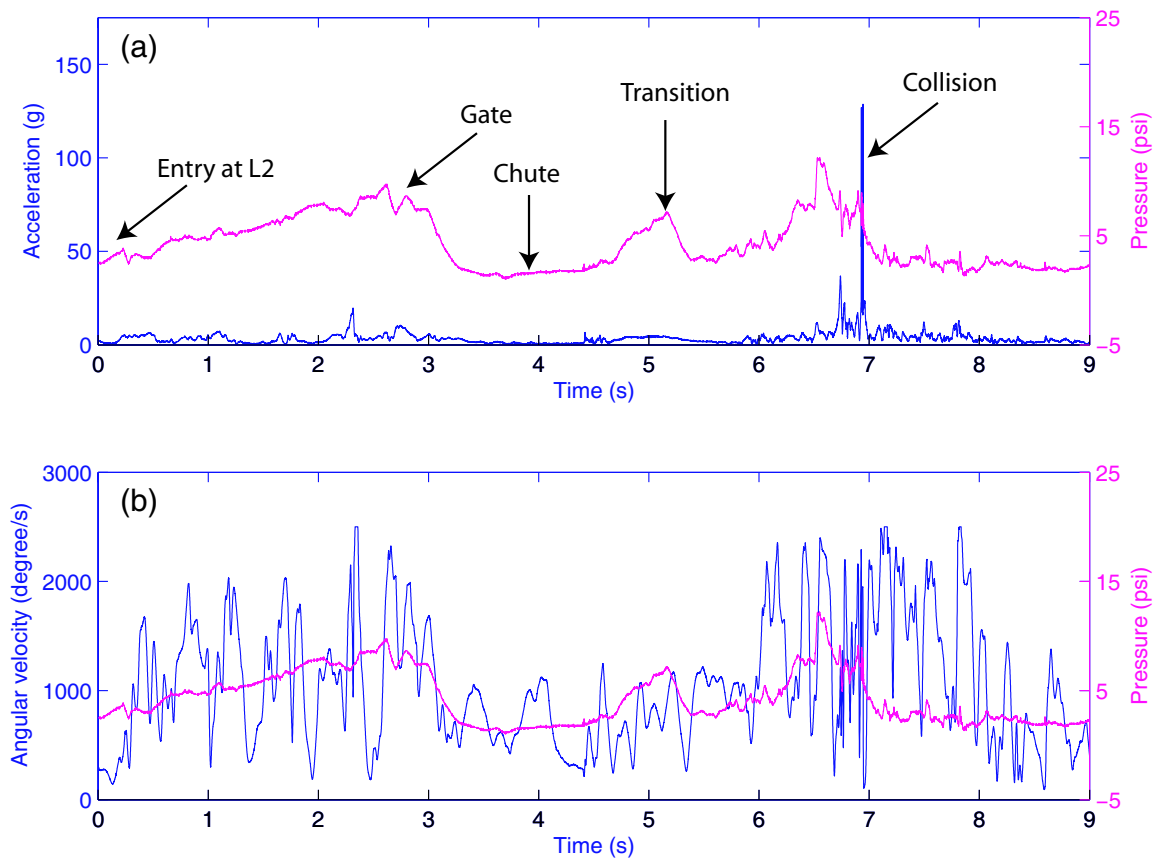

Figure 3.6. An example of measurements by Sensor Fish released from the left edge of the vortex (Location L2) : (a) acceleration; (b) angular velocity.
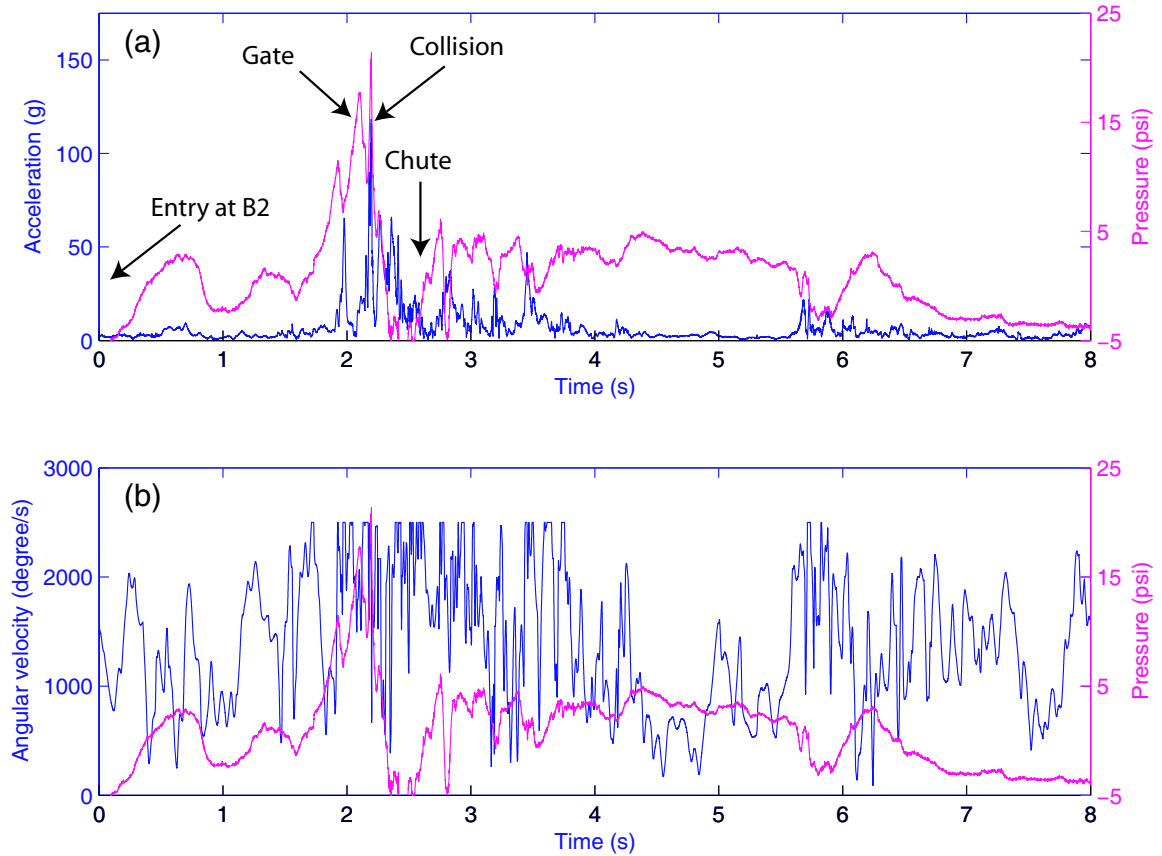

Figure 3.7. An example of measurements by Sensor Fish released from the back edge of the vortex (Location B2) : (a) acceleration; (b) angular velocity. 

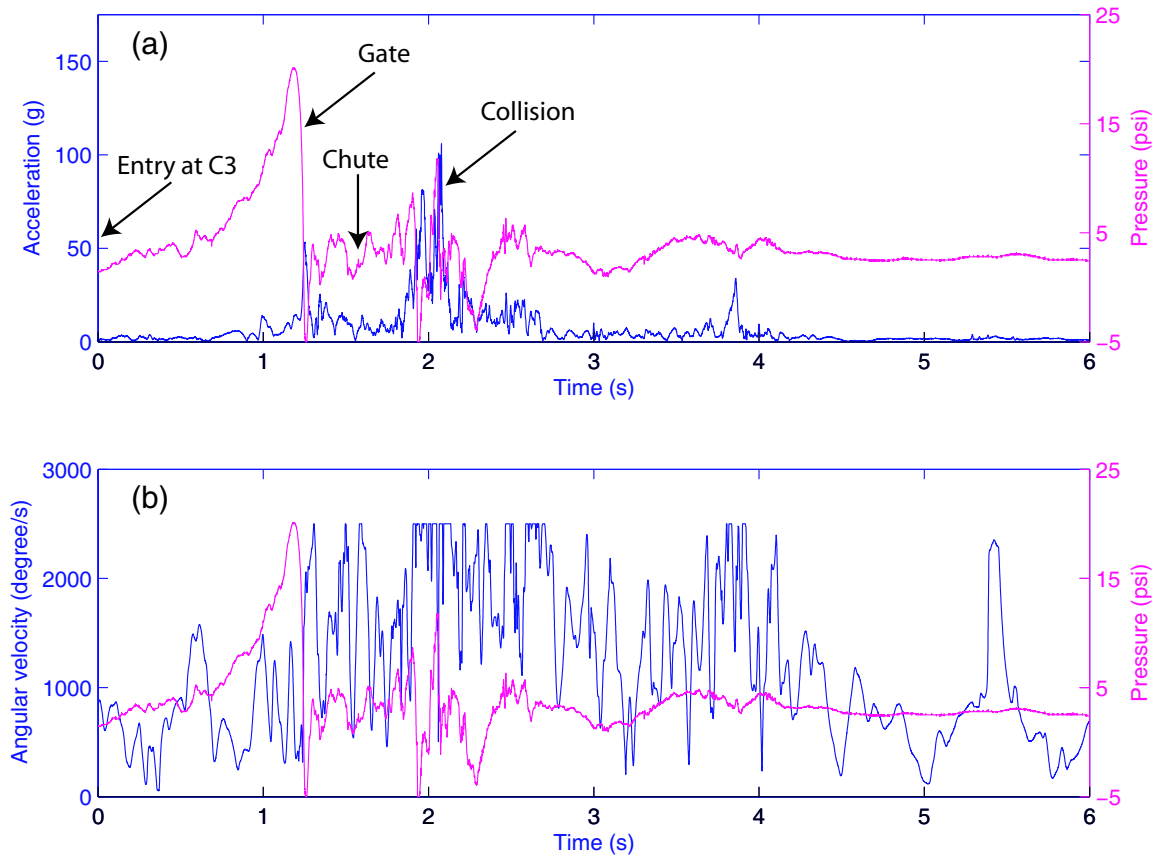

Figure 3.8. An example of measurements by Sensor Fish released from the core of the vortex (Location C3) : (a) acceleration; (b) angular velocity.
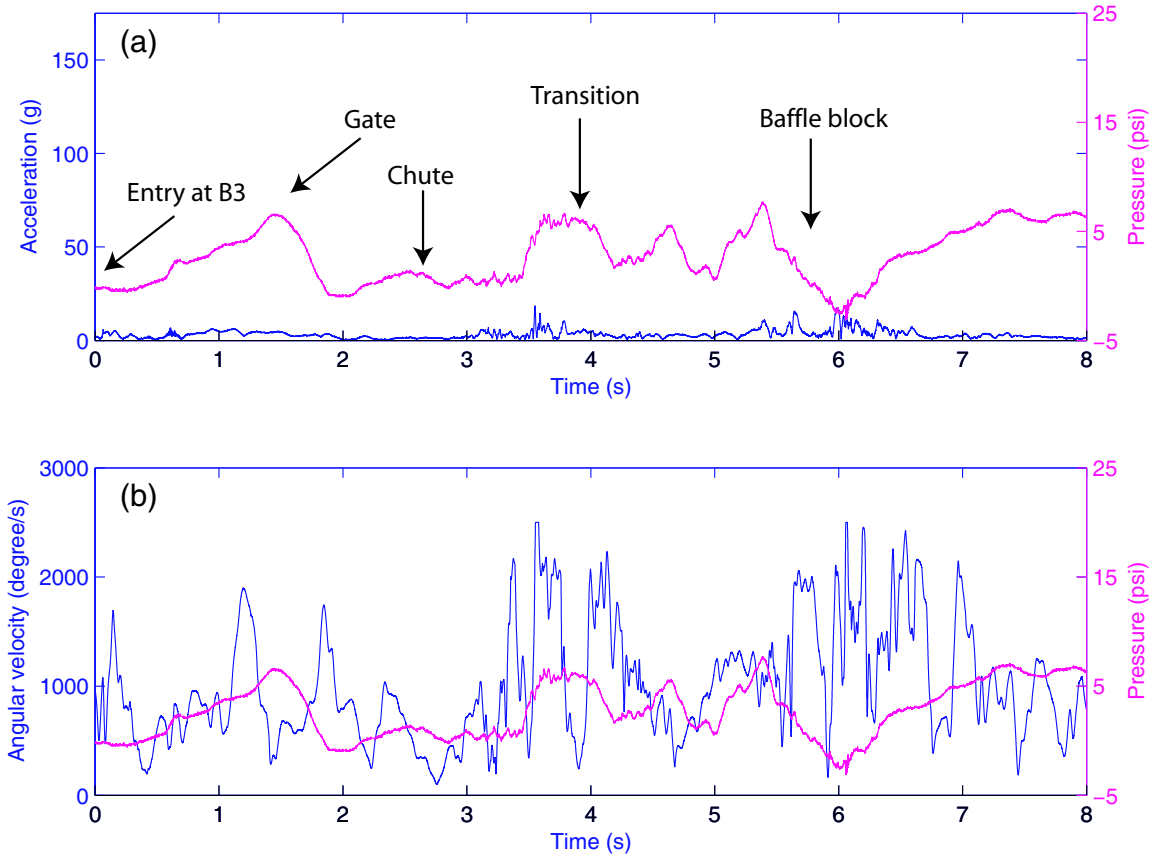

Figure 3.9. An example of Sensor Fish passage without severe events measurements (Location B3) : (a) acceleration; (b) angular velocity. 

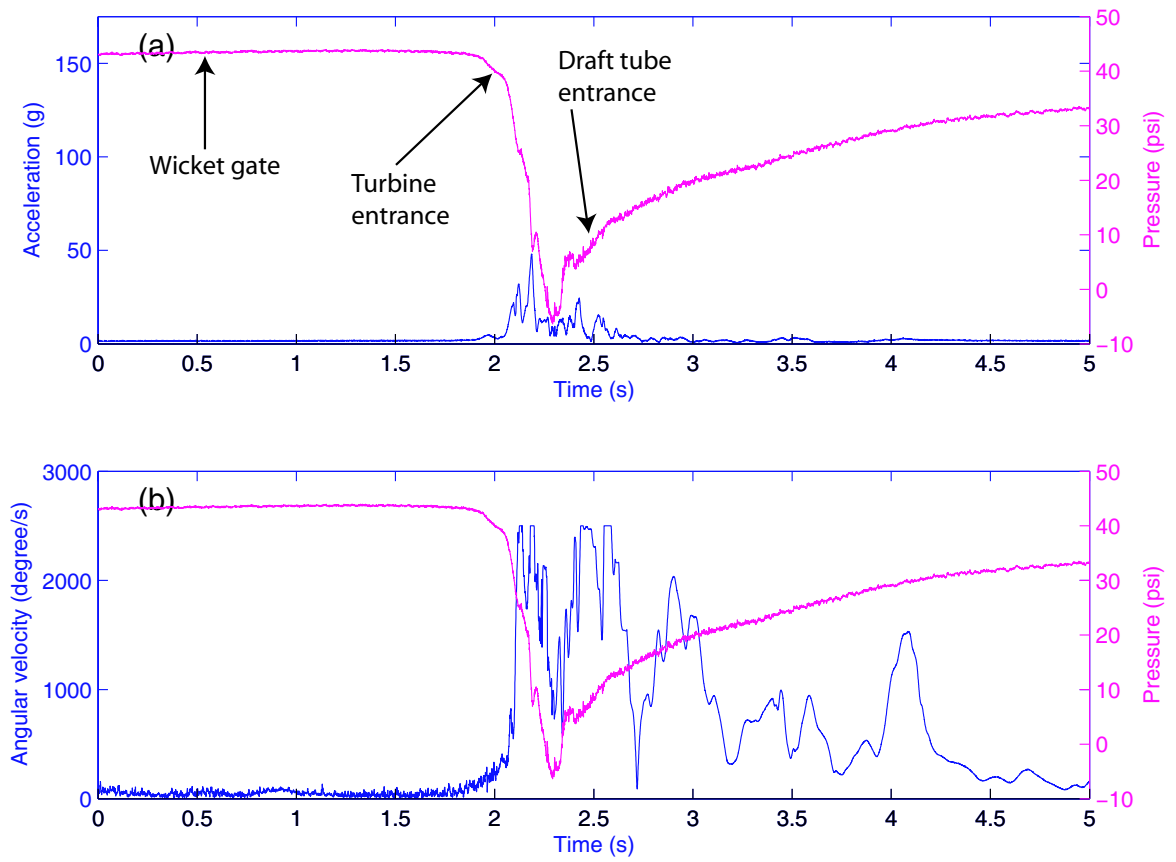

Figure 3.10. An example of measurements by Sensor Fish passing through Unit 9 turbine at Wanapum Dam, 17kcfs : (a) acceleration; (b) angular velocity. 


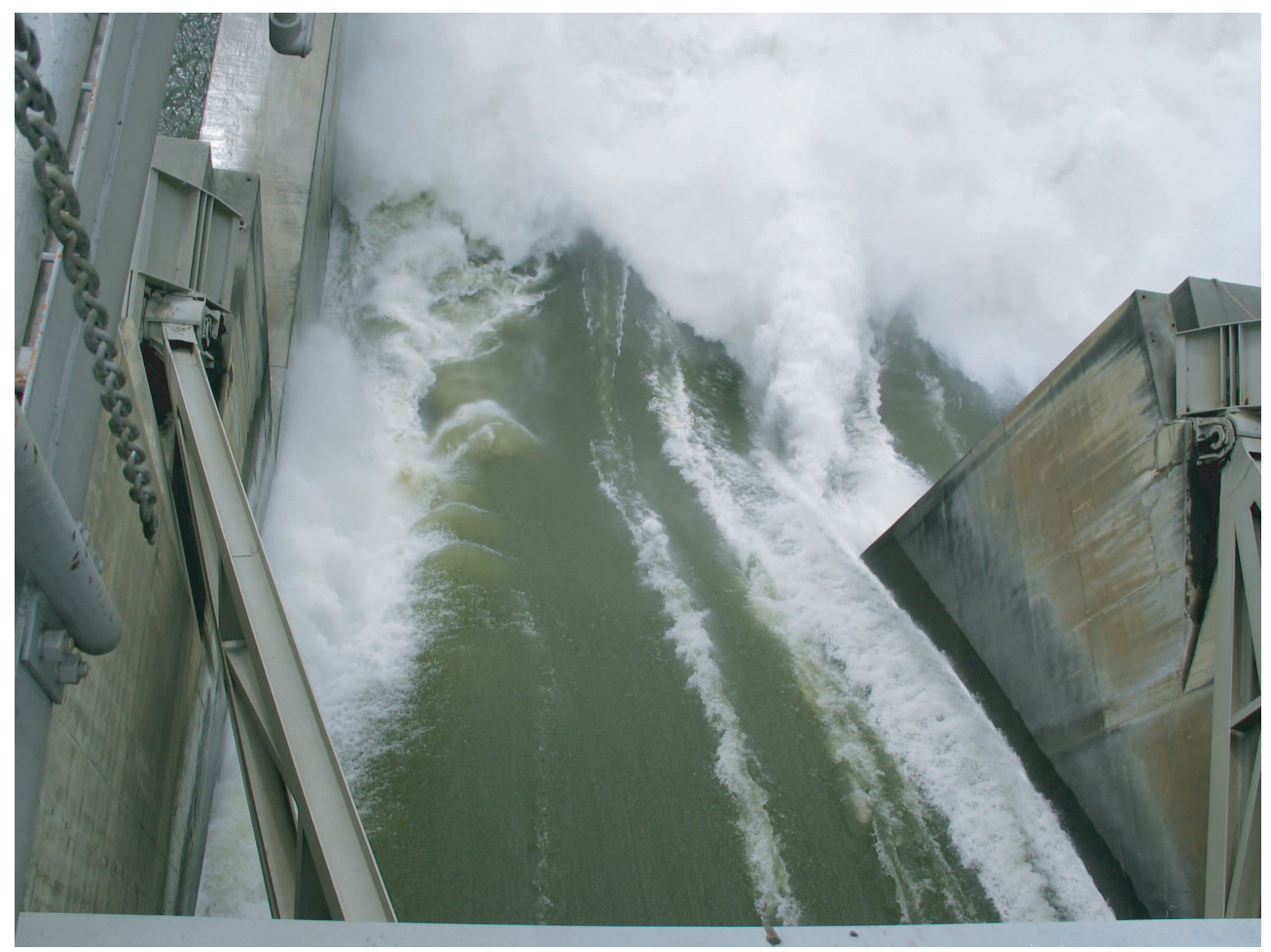

Figure 3.11. Flow in the spillbay 6 at a discharge of $20 \mathrm{kcfs}$, The Dalles Dam 


\subsection{Conclusions and Recommendations}

From this pilot study of releasing Sensor Fish in the surface of the vortex at spillbay 6 at the Dalles Dam in April 2006, we determined the following:

- Surface release procedures for Sensor Fish were successful and can be used in future studies.

- Sensor Fish deployed from the surface experienced more "severe conditions" than those released from mid-bay at Bays 4 and 6.

- The large angular velocity experienced by Sensor Fish within the vortex is comparable to that experienced by Sensor Fish passing through a turbine. In some sense, the flow in the vortex at spillway 6 is analogous to the swirling downward flow around a turbine.

- To understand the hydraulic impact of a vortex on juvenile fish, the full study must be completed to collect more samples of vortex-entrained Sensor Fish to compare directly with entrained and non-entrained Sensor Fish released upstream of the vortex under more typical entrainment conditions.

- If possible, pipes and other objects which are upstream and in the vortex should be relocated or removed, and unnecessary non-uniform approach flow and entrainment should be avoided. However, it is recognized that a release pipe system will need to be placed upstream of the vortex for the biological test.

- A more flexible release pipe system is needed for spillway studies. The system should have more range of motion vertical and parallel to the spillway to address the obvious variability of spillway hydraulic and fish exposure conditions in both vertical and horizonal directions. Preliminary engineering analysis should be performed to determine whether such a system can be economically constructed to withstand static and dynamic loads over the range of expected discharge and in the presence of an unsteady vortex. 



\subsection{References}

Carlson T and J Duncan. 2003. Evolution of the Sensor Fish Device for Measuring Physical Conditions in Severe Hydraulic Environments. DOE/ID-11079, Pacific Northwest National Laboratory.

Deng Z, GR Guensch, CA McKinstry, RP Mueller, DD Dauble, and MC Richmond. 2005. "Evaluation of fish-injury mechanisms during exposure to turbulent shear flow." Canadian Journal of Fisheries and Aquatic Sciences 62(7):1513-1522.

Deng Z, MC Richmond, C Simmons, and T Carlson. 2004. Six Degrees of Freedom Sensor Fish Design: Governing Equations and Motion Modeling. PNNL-14779, Pacific Northwest National Laboratory.

Normandeau A, JR Skalski, and I Mid Columbia Consulting. 2003. Estimated direct mortality and injury of juvenile salmonids in passage through The Dalles spillway, Columbia River in spring and summer 2002. Report prepared for U.S. Army Corps of Engineers, Portland District.

Normandeau A, JR Skalski, and I Mid Columbia Consulting. 2004. Direct effects of differential spill volumes on mortality and injury rates of juvenile salmonids at The Dalles Dam spillway, Columbia River in fall 2002 and spring 2003. Report prepared for U.S. Army Corps of Engineers, Portland District.

Normandeau A, JR Skalski, and I Mid Columbia Consulting. 2005. Evaluation of the spillway diversion wall on survival and injury of juvenile Chinook salmon at The Dalles Dam, spring 2004. Report prepared for U.S. Army Corps of Engineers, Portland District.

Odgaard J. 1986. "Free surface air-core vortex." ASCE Journal ofHydraulic Engineering 112(7):610620.

Rankine W. 1858. Manual of applied mechanics. C. GriffenCo, London, U.K.

Richmond MC, Z Deng, CA McKinstry, RP Mueller, DD Dauble, and T Carlson. 2006. "Correlating the Biological Response of Juvenile Fish and an Autonomous Sensor to Turbulent Shear Flows." To be submitted to Canadian Journal of Fisheries and Aquatic Sciences. 



\section{Appendix A}

Sensor Fish Data Showing Pressure, Acceleration Magnitude, and Angular Velocity Magnitude Time Histories for Each Release 



\section{Appendix A - Sensor Fish Data Showing Pressure, Acceleration Magnitude, and Angular Velocity Magnitude Time Histories for Each Release}

For completeness, all 12 releases are included this appendix. Refer to Fig. 2.4 for details of release locations.
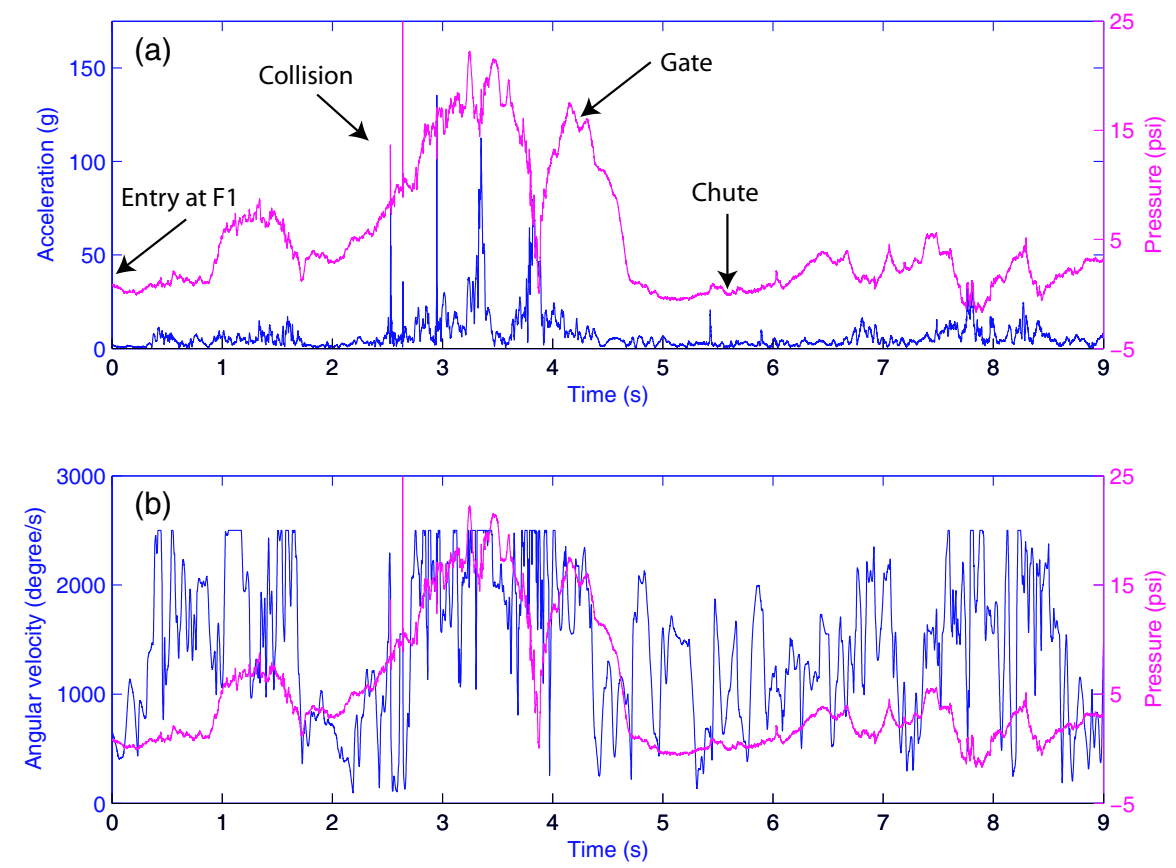

Figure A.1. An example of measurements by Sensor Fish released from the front edge of the vortex (Location F1) : (a) acceleration; (b) angular velocity. 

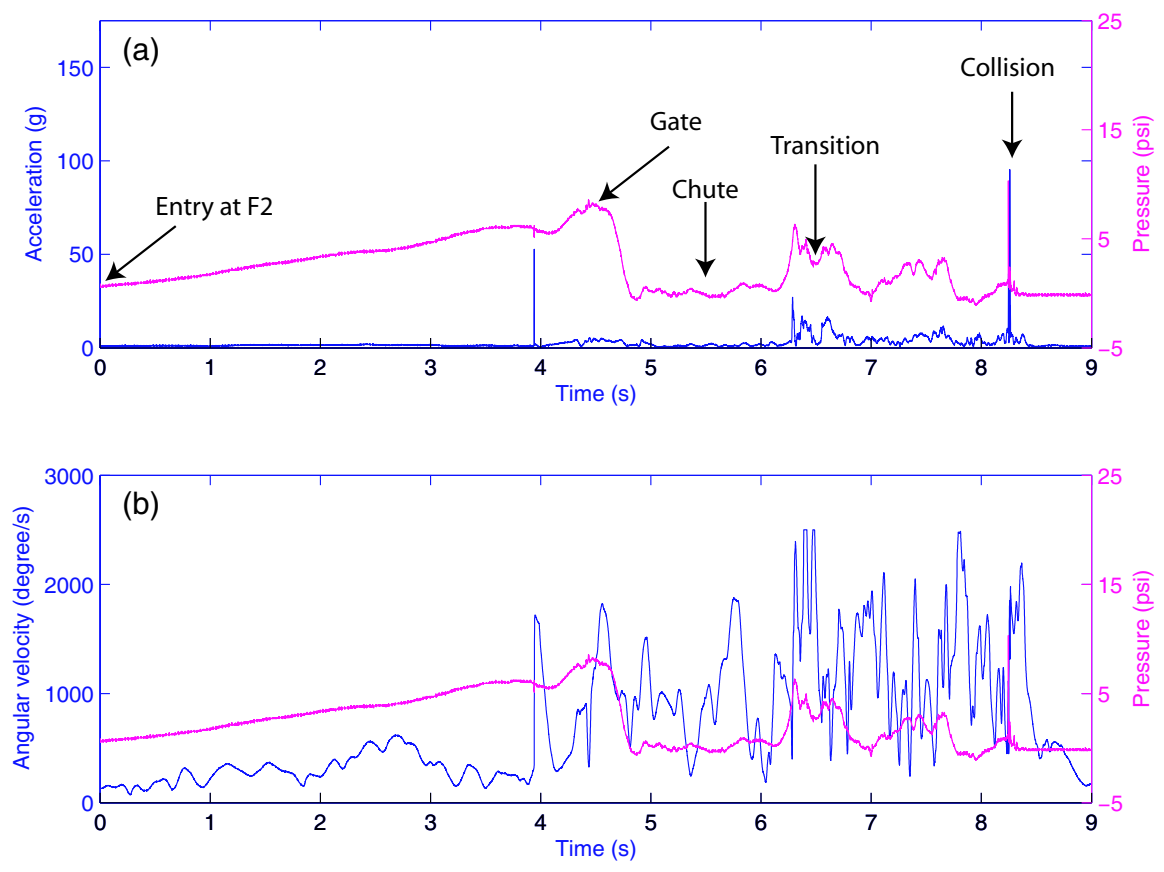

Figure A.2. An example of measurements by Sensor Fish released from the front edge of the vortex (Location F2) : (a) acceleration; (b) angular velocity.
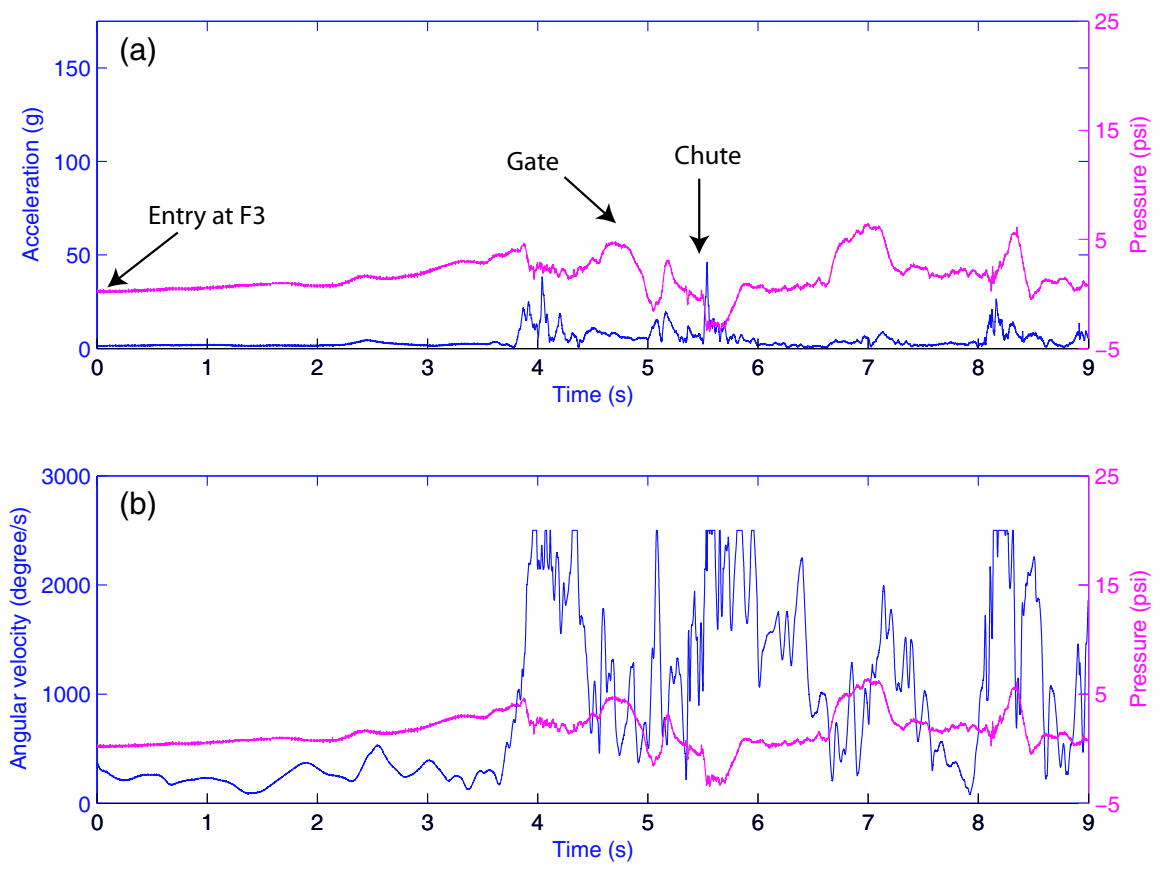

Figure A.3. An example of measurements by Sensor Fish released from the front edge of the vortex (Location F3) : (a) acceleration; (b) angular velocity. 

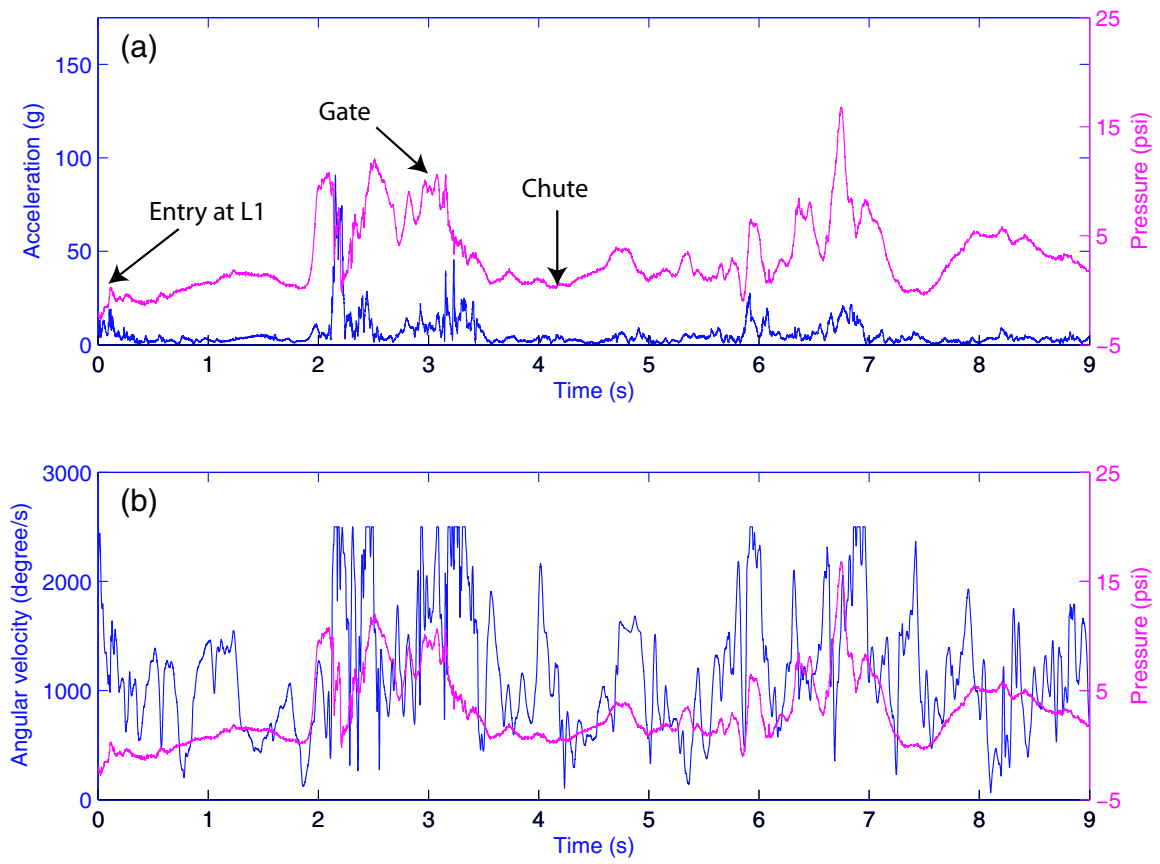

Figure A.4. An example of measurements by Sensor Fish released from the left edge of the vortex (Location L1) : (a) acceleration; (b) angular velocity.
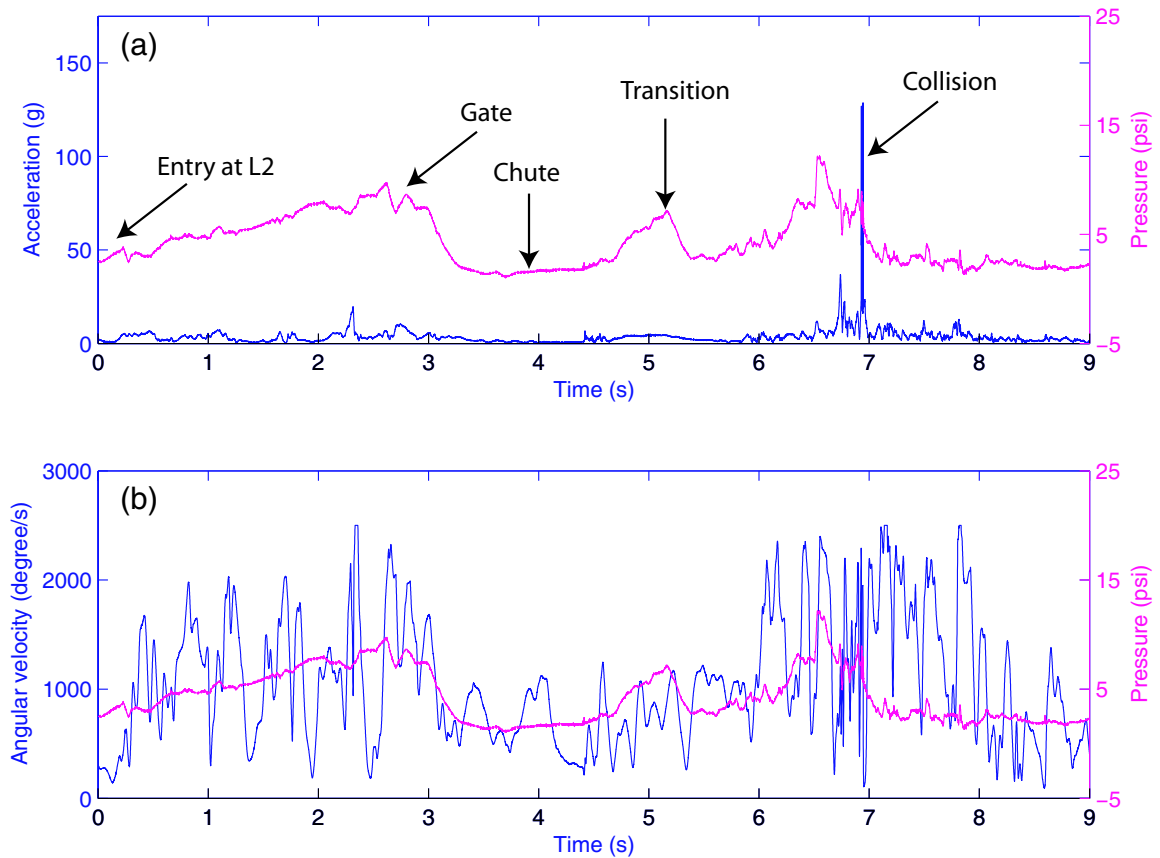

Figure A.5. An example of measurements by Sensor Fish released from the left edge of the vortex (Location L2) : (a) acceleration; (b) angular velocity. 

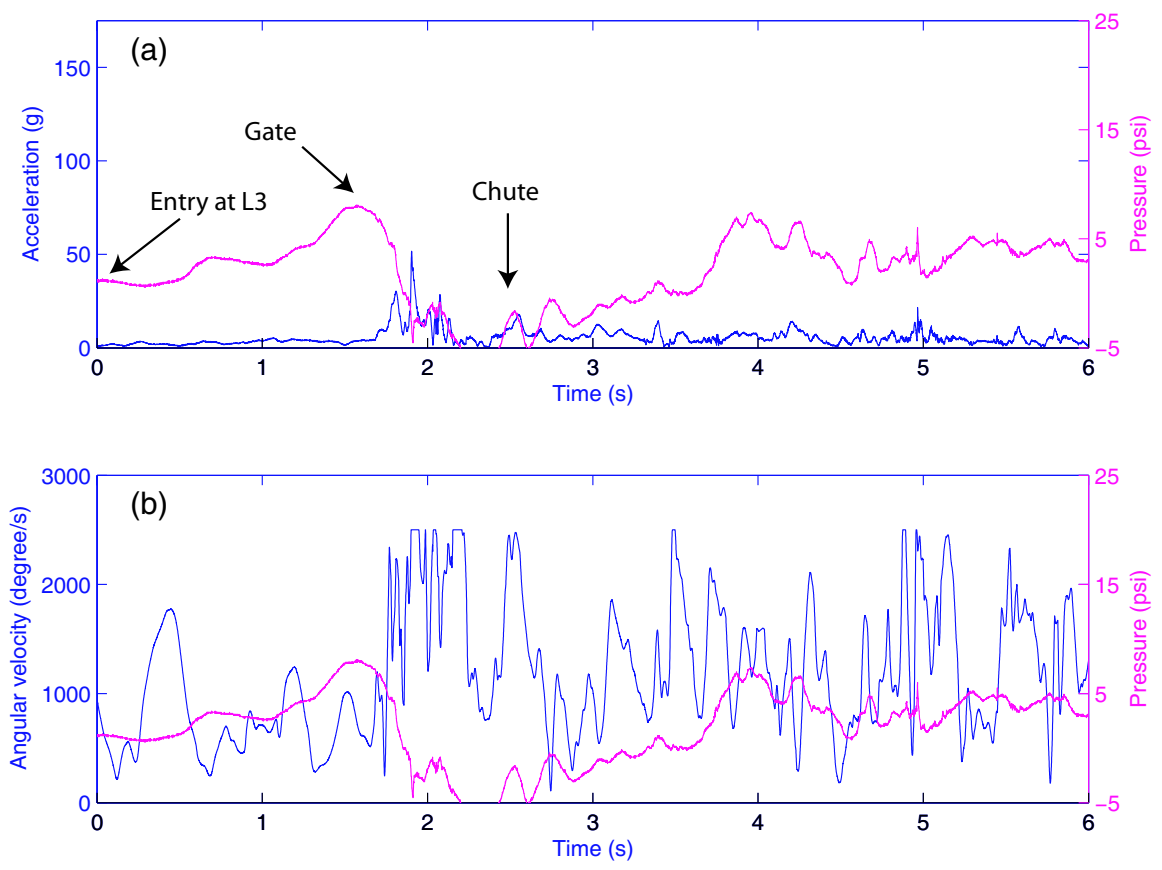

Figure A.6. An example of measurements by Sensor Fish released from the left edge of the vortex (Location L3) : (a) acceleration; (b) angular velocity.
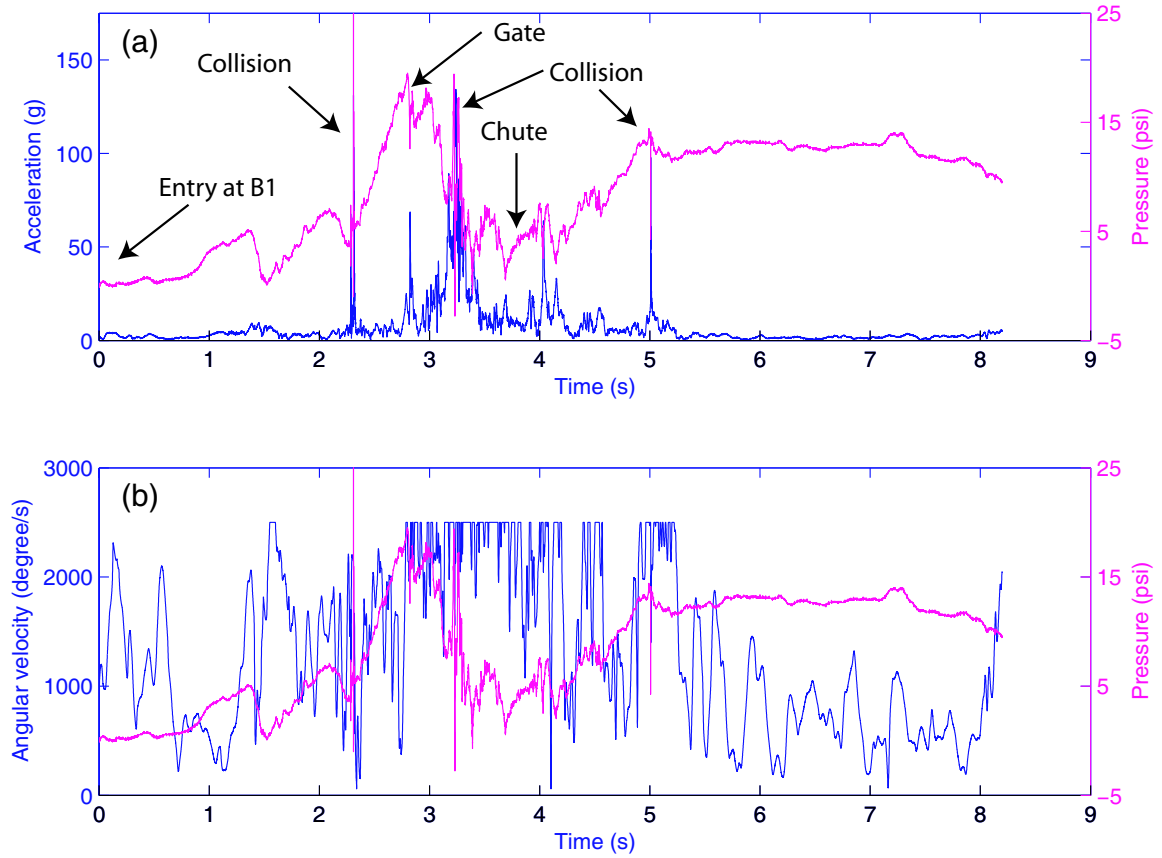

Figure A.7. An example of measurements by Sensor Fish released from the back edge of the vortex (Location B1) : (a) acceleration; (b) angular velocity. 

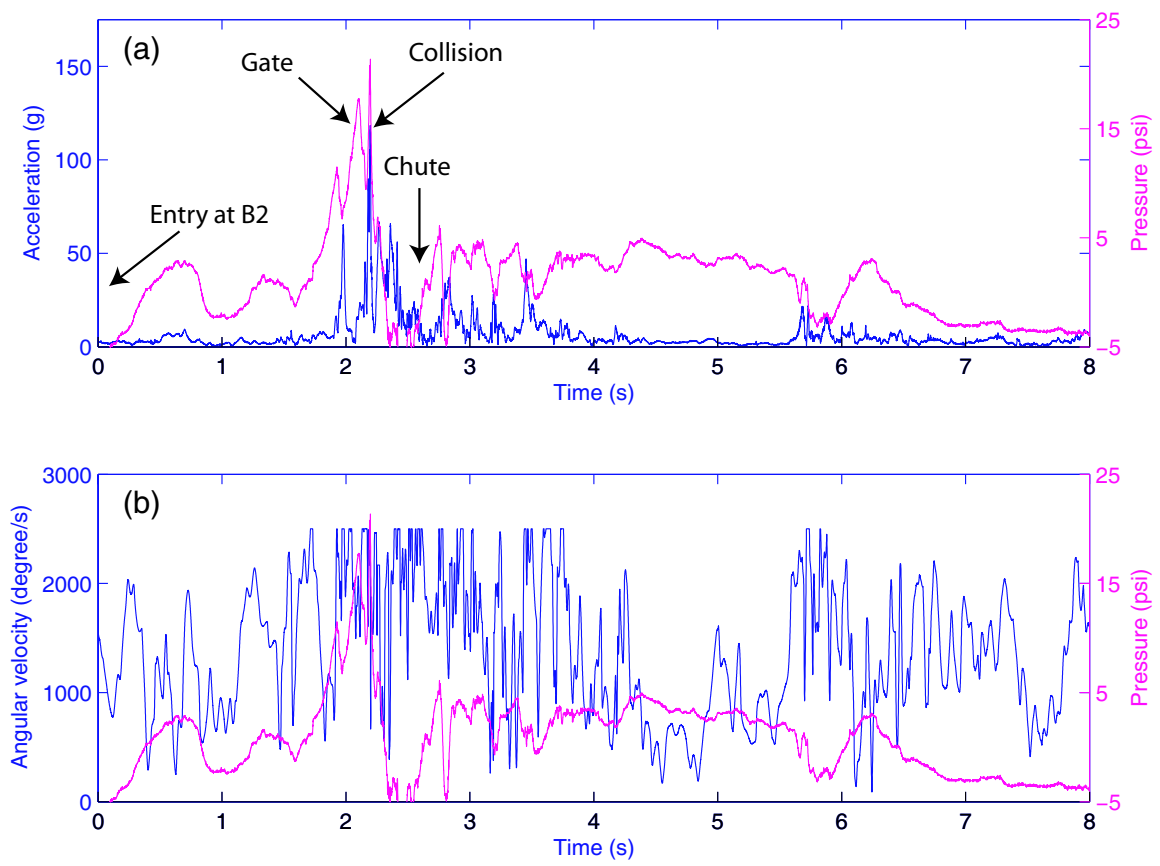

Figure A.8. An example of measurements by Sensor Fish released from the back edge of the vortex (Location B2) : (a) acceleration; (b) angular velocity.
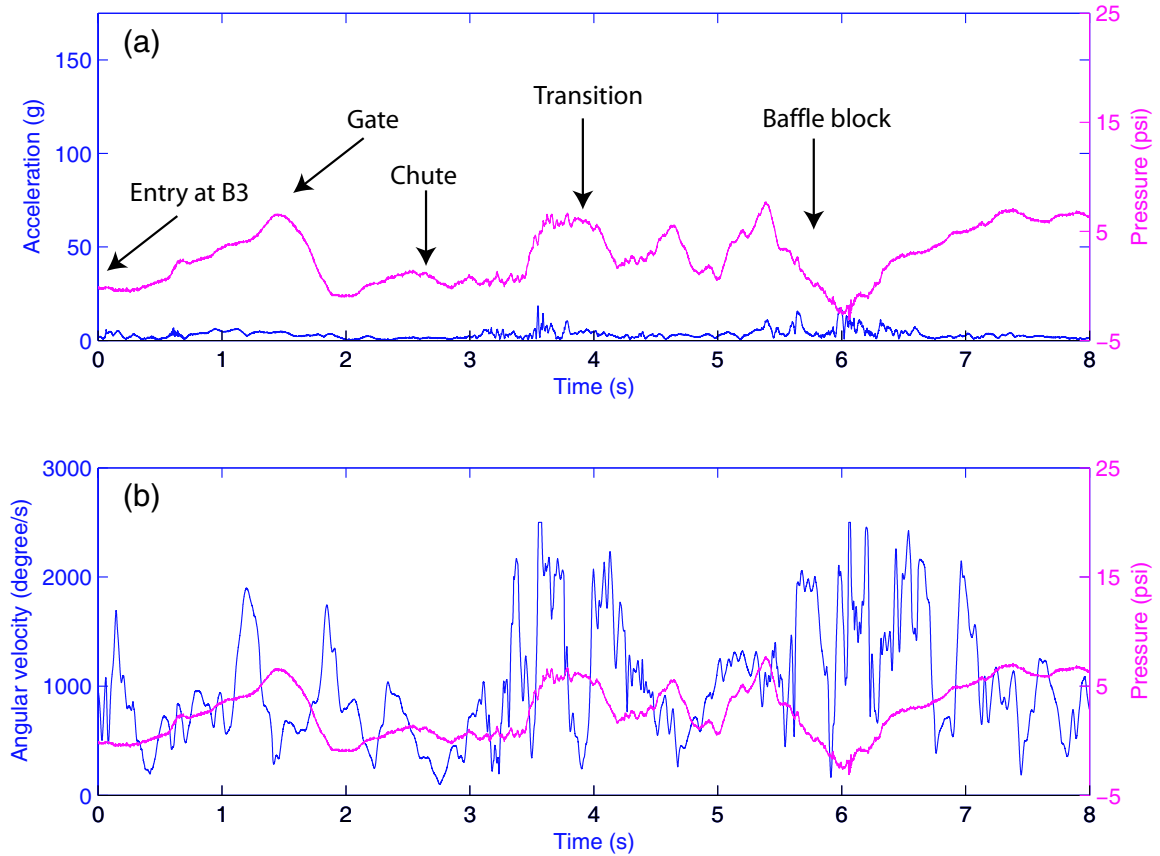

Figure A.9. An example of measurements by Sensor Fish released from the back edge of the vortex (Location B3) : (a) acceleration; (b) angular velocity. 

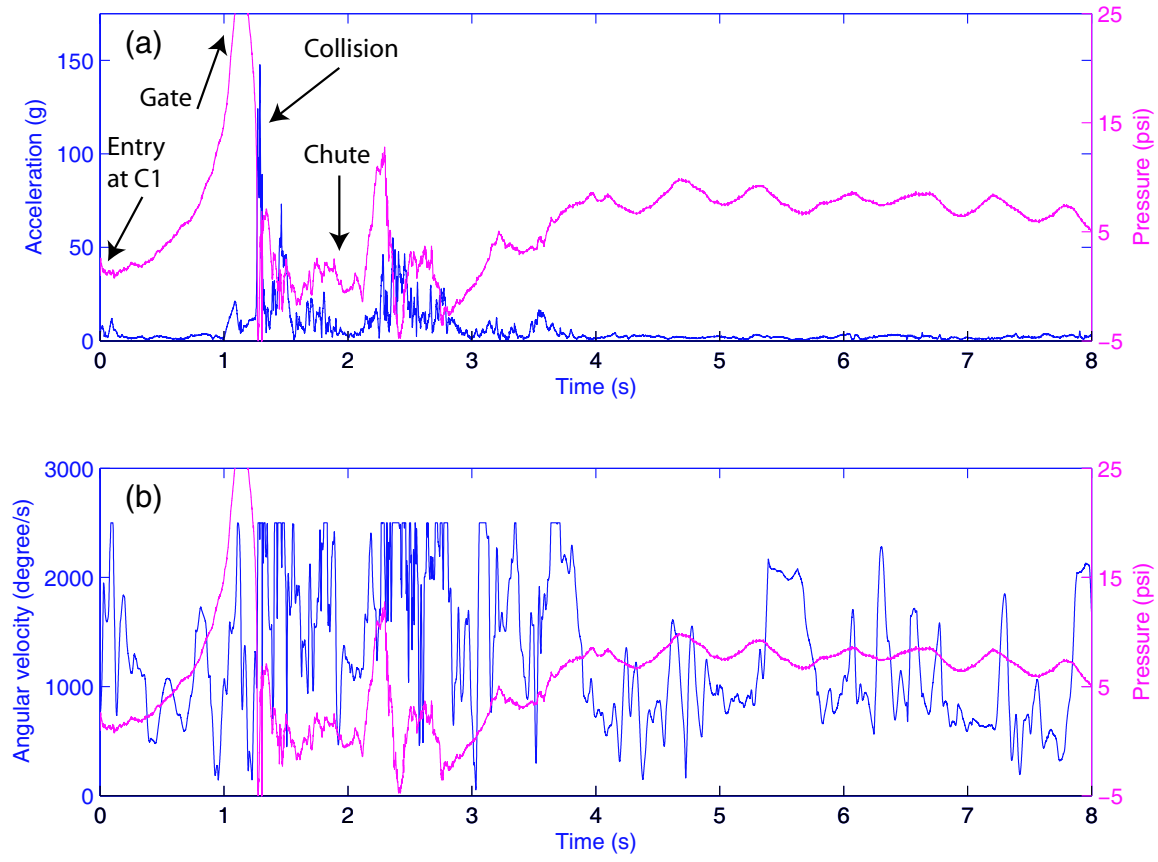

Figure A.10. An example of measurements by Sensor Fish released from the core of the vortex (Location C1) : (a) acceleration; (b) angular velocity.
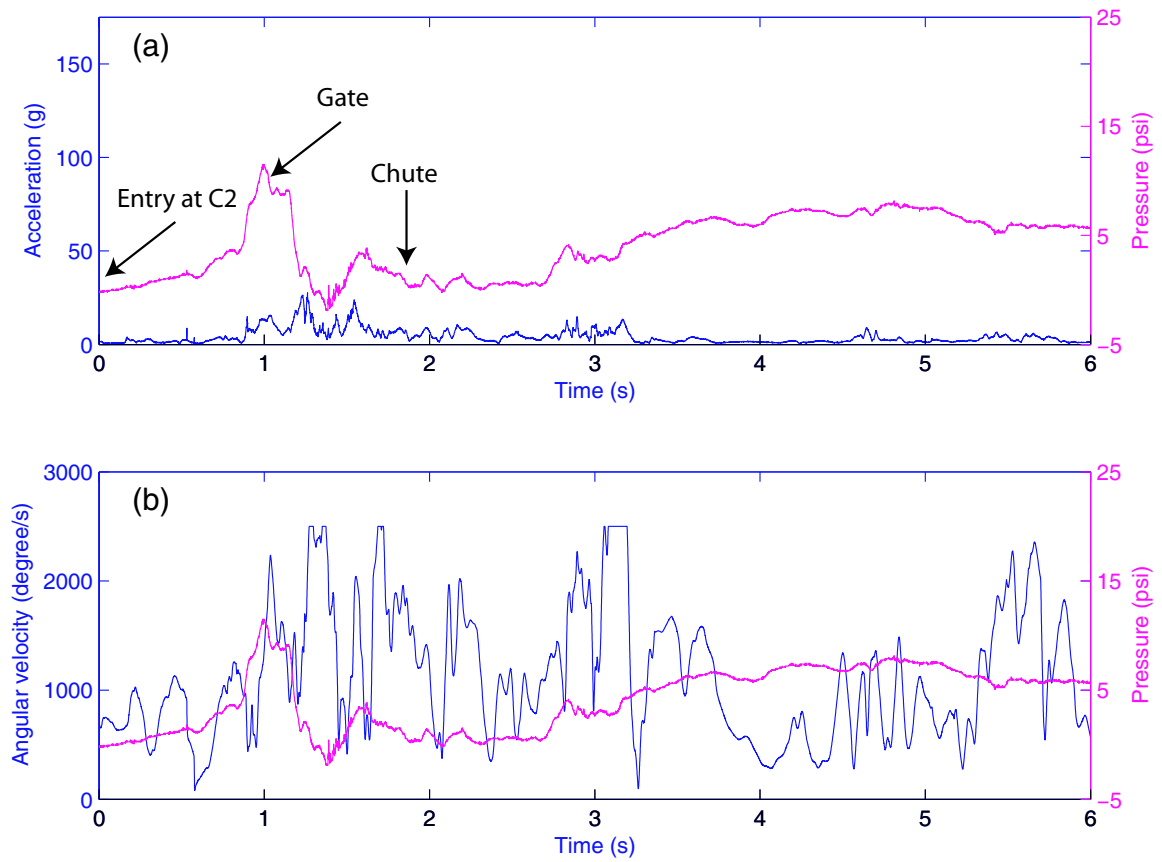

Figure A.11. An example of measurements by Sensor Fish released from the core of the vortex (Location C2) : (a) acceleration; (b) angular velocity. 

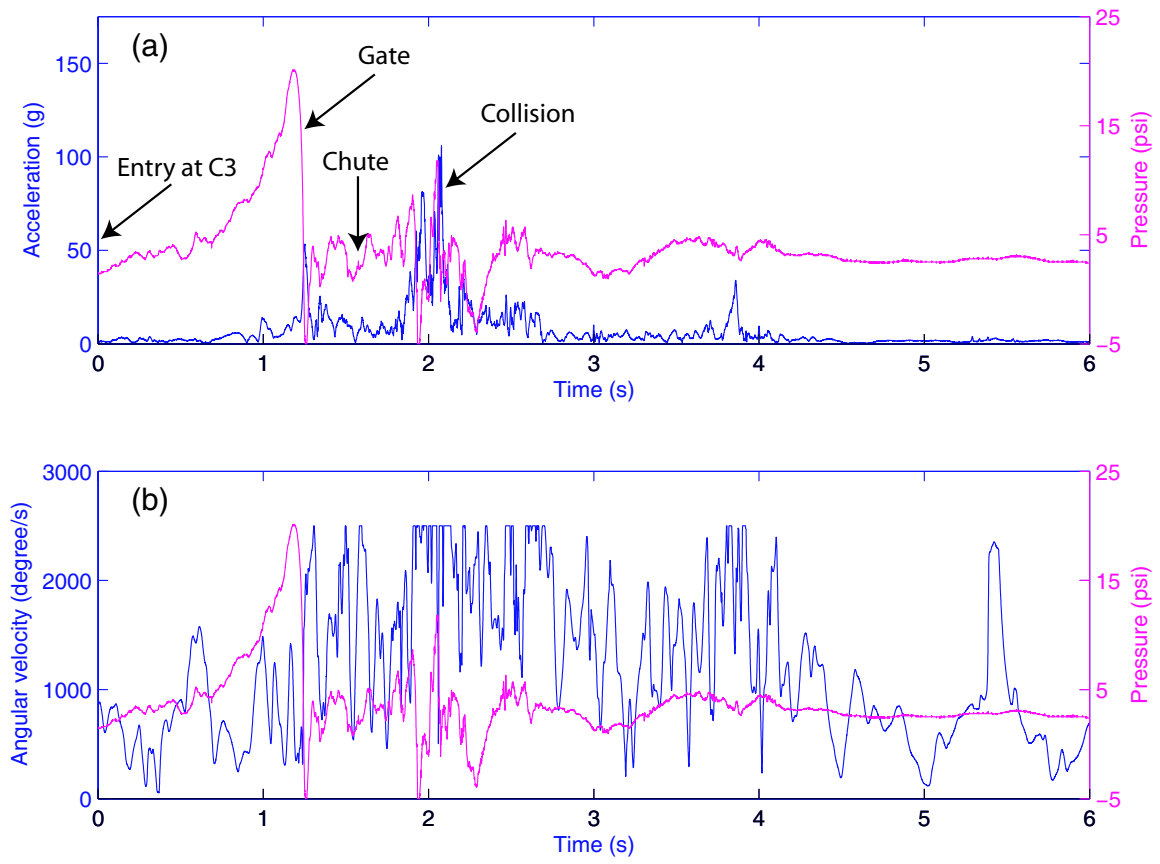

Figure A.12. An example of measurements by Sensor Fish released from the core of the vortex (Location C3) : (a) acceleration; (b) angular velocity. 